Portland State University

PDXScholar

$11-16-2018$

\title{
Naturalizing Knowledge: The Project of Evolutionary Epistemology
}

Dmitriy Cherchenko

Portland State University

Follow this and additional works at: https://pdxscholar.library.pdx.edu/honorstheses Let us know how access to this document benefits you.

\section{Recommended Citation}

Cherchenko, Dmitriy, "Naturalizing Knowledge: The Project of Evolutionary Epistemology" (2018).

University Honors Theses. Paper 639.

https://doi.org/10.15760/honors.654

This Thesis is brought to you for free and open access. It has been accepted for inclusion in University Honors Theses by an authorized administrator of PDXScholar. Please contact us if we can make this document more accessible: pdxscholar@pdx.edu. 
Naturalizing Knowledge: The Project of Evolutionary Epistemology

by

Dmitriy Cherchenko

An undergraduate honors thesis submitted in partial fulfillment of the requirements for the degree of

Bachelor of Science

in

University Honors

and

Philosophy

Thesis Advisor

Dr. Angela Coventry

Portland State University

2018 
Abstract

Traditional epistemology deals with questions about the possible sources of knowledge, the conditions which make a belief an item of knowledge, and the extent to which we can know, as well as the nature of justification and what can make a belief justified for someone. Evolutionary epistemology (EE) breaks from TE to avoid its perceived shortcomings by both dismissing some traditional questions and emphasizing new, related questions that are more readily answerable given what we know about the biology and phylogenetic history of humans. The new questions assume that we are physical, naturally evolved beings and that cognition can be studied by methods of natural science. This thesis reviews the emergence of EE, summarizing the arguments that have been made by its major proponents, clarifies two points that are neglected in the literature, and ends with a discussion of some criticisms and limitations of EE as well as work that remains to be done. The first point I clarify is that the program in EE of studying the evolution of epistemological mechanisms (EEM) is logically distinct from the program of building an evolutionary epistemology of theories (EET). I argue that EET does not gain validity from the fact that cognitive mechanisms have evolved and does not stand or fall with EEM. The second point I clarify is that adherents to EE need not see it as replacing or superseding TE. A complementary view of EE with TE is both viable and potentially fruitful. 
Naturalizing Knowledge: The Project of Evolutionary Epistemology

As an area of philosophical inquiry, epistemology deals with theory of knowledge and the topic of justified belief. Included among the questions of epistemology are questions about the possible sources of knowledge, the conditions which make a belief an item of knowledge, and the extent to which we can know. Concerning justified belief, the problems concern the nature of justification and what can make a belief justified for someone (Steup 2005). We need to either explain how it's possible to acquire knowledge and justified beliefs, or, unless we assume that some things are in fact known, we should determine whether knowledge is altogether impossible. This epistemology has been around since Plato’s days. Call it traditional epistemology (TE).

We shall distinguish TE from the evolutionary approach, which includes the naturalistic, or naturalized, approach to epistemology. Evolutionary epistemology (EE) is not an entirely different thing; otherwise there'd be no point in drawing a contrast. EE breaks from TE to avoid its perceived shortcomings by both dismissing some traditional questions and emphasizing new, related questions that are more readily answerable given what we know about the biology and phylogenetic history of humans. The new questions assume that we are physical, naturally evolved beings in a natural world and that our cognition can be studied by methods of natural science (Campbell 1987, p. 165). Some proponents of this position argue that no progress, or at least not much progress, had been made in TE, and they argue that science can help answer questions of epistemology (Bradie and Harms 2017; Quine 1969). In particular, the focus of study is how we as natural beings learn and adapt and what affects our belief-forming processes.

EE organizes a set of core premises which are used for concrete philosophical and scientific theories explaining cognition and learning processes. It is naturalistic in its emphasis of using concepts and methods that are valid in the natural sciences and in its dedication to some ontological and epistemological realism as presupposed in science. The EE approach grounds 
theories in experience by starting with what we know from science rather than with what we know a priori. EE is aimed mostly at providing descriptive accounts of knowledge and only minimal, if any, normative conclusions. Finally, EE is interdisciplinary to the extent that it views knowledge and learning as phenomena to be studied by the methods of evolutionary biology, psychology, and philosophy.

The first core principle of EE is that humans and their organs, like all other animals with their organs, have evolved naturally and that this indicates that some aspects of the way we think can be explained in evolutionary terms. The brain, central nervous system, and the associated components of the ratiomorphic apparatus - the sum of all information-gaining and informationprocessing organs (Wuketits 1990, p. 77) — have evolved naturally and are constrained by their phylogenetic history, so it seems reasonable to suppose that the biological theory of evolution can contribute to the study of epistemological mechanisms. As Donald Campbell, the person who coined the term evolutionary epistemology, puts it, "An evolutionary epistemology would be at minimum an epistemology taking cognizance of and compatible with man's status as a product of biological and social evolution" (1974, p. 413).

In his early work in EE, Campbell developed the influential metaphor taking the process of evolution itself as a learning and cognition process. The ratiomorphic apparatus is thus an abstraction from any particular physical substrates of cognition, in this broadly metaphorical sense, as it's present in essentially all life; so the human ratiomorphic apparatus is the object of study in epistemology. Viewing evolution as cognition has become a core theme in EE, the aim being to capture the idea that the way information changes through phylogenesis and is stored in DNA is analogous to the way an organism learns and develops during its lifetime, a process of ontogenesis. Thus EE discards most of the distinction between phylogenesis and ontogenesis, even though in evolutionary biology it is recognized that models of phylogenesis account for 
change in terms of mechanisms significantly different from the mechanisms that account for an organism's development during its lifetime (Gontier 2006, pp. 11-12; Bradie and Harms 2017). This move in EE is not accidental. It is due to another major program in EE, which is about describing cultural learning and change, especially theory change in science, using evolutionary theory. Here the scientific theory of organic evolution is applied to explain, and sometimes to justify, the development of science.

This thesis reviews the historical emergence of EE as a field in philosophy, summarizing the arguments that have been made by its major proponents, clarifies two points that appear to be neglected in the literature, and ends with a discussion of some criticisms and limitations of EE as well as work that remains to be done. The first point I'll clarify is that the program in EE of studying the evolution of epistemological mechanisms (EEM) is logically distinct from the program of building an evolutionary epistemology of theories (EET). I argue that EET does not gain validity from the fact that cognitive mechanisms have evolved and does not stand or fall with EEM. The second point I'll clarify is that adherents to EE need not, contrary to the opinion of some philosophers, see it as replacing or superseding TE. A complementary view of EE with TE is both viable and potentially fruitful.

\section{Historical Background and Philosophical Motivations for EE}

As all important ideas in philosophy, evolutionary epistemology did not appear in a vacuum, and its precursors may be noticed even in writings by Hume and Locke. To be sure, it was only in the early 20th century that there appeared specifically evolutionary epistemologies in the Darwinian sense, after evolutionary science acquired its broad acceptance. The following section is organized to highlight the shortcomings of traditional approaches to epistemology and to explain the motivations for a new, naturalistic, evolutionary approach. 


\section{Early Modern Epistemology's Relevance to EE}

The foundationalist approach of Descartes, sometimes considered the start of the modern or early-modern era of epistemology, exemplifies what I'm here calling traditional epistemology. Descartes recognized that we should not simply presume that we have reliable sensory access to the external world or that we are fully capable of valid inference. Each of these two possibilities and any other claim, if not so obvious that it cannot be consistently doubted, needs to be shown by way of argument. The proposed method requires us to "raze everything to the ground" before we carefully admit only those beliefs which cannot be doubted, which make the foundations upon which beliefs can be firmly based (Ariew \& Watkins 2009, pp. 40-41). Thus Descartes begins by subjecting every belief to total scrutiny, building upon undoubtable truths and deriving other acceptable beliefs. Furthermore, Descartes takes his knowledge of the necessary existence of an omnipotent, benevolent, non-deceiving God as what many other beliefs depend on, and he even mounts an argument for the existence of external material things on the premise that God would not allow him to be totally mistaken about his sensory perceptions (pp. 51, 60-61, 64).

Descartes relates to EE in a couple different ways. One lesson is that Descartes's starting point offers him no straightforward way to establish much, such the reliability of our senses, without relying on an omnipotent and benevolent God or something providing the same trusted grounding. Descartes's position on this issue served more as a springboard against which EE and naturalistic epistemology in general offered a non-foundationalist approach (Quine 1990, p. 19). EE views Descartes's efforts as demonstrating the shortcomings of the foundationalist approach, and instead EE suggest that we lend credence to beliefs, not based on our inability to doubt them, but on their reliability for our living conditions (Campbell 1987, p. 166).

Additionally, EE discards the suggestion that the mind is an immaterial thing but picks up the important thesis that the mind has innate truths and capacities (c.f., the third Meditation). In 
fact, years before Descartes, Bacon had written that the human mind has innate tendencies, especially to think in certain fallacious ways because of the idola tribus that plague the mind (New Organon, Book 1.41). EE accepts that our cognitive faculties are shaped by innate structures—innate hypotheses actually, as we'll see (Riedl 1984, pp. 40-44). But all innate components of the mind become the facts that need a naturalistic explanation, consistent with evolutionary science, and no longer invoking the works of a God. ${ }^{1}$

Insofar as naturalistic epistemology emphasizes empirical experience, it appears to have roots among philosophers such as John Locke and David Hume, who emphasized empirical experience as the ultimate source of any of our beliefs. This position was admitted as the starting point in later epistemologies that emphasized our biological constraints as beings in nature.

About Locke, we should note that he believed that each person assumes there is an external world even though you can't prove it. Locke believed that you could get yourself to doubt external reality only as an academic exercise, and the human mind works in a way that enables us to get around and do whatever we need for our survival and wellbeing. Our mental faculties, though often imperfect for abstract concepts, are "suited ... to the preservation of us in whom they are, and accommodated to the use of life, they serve to our purpose well enough" (Ariew \& Watkins 2009, p. 413, An Essay IV.XI.8). So our cognitive faculties are sufficient for any practical needs we have. This view is consistent with the claim in EE that evolution has built a realist conception of the world into the ratiomorphic apparatus, so it does not matter what abstract philosophical views you have so long as you act as if you're a realist about the world.

Hume advances the view that we rely on reasoning principles that are not demonstrably

${ }^{1}$ Consider the contrast with Descartes: "it is not astonishing that in creating me, God should have endowed me with this idea [that there is a God], so that it would be like the mark of the craftsman impressed upon his work" (Ariew \& Watkins 2009, p. 53, Meditations 3). 
justifiable as are, for example, theorems of mathematics. Hume shows that some of the ways we think, such as certain kinds of inference, are driven by custom or habit even though stemming from past empirical experiences. Take the prime example of the relation of cause and effect, on which is founded all reasoning dealing with matters of empirical fact (EHU IV.I.4). ${ }^{2}$ Causal inference is not determined by a process of reasoning or by knowledge of "the secret power by which the one object produces the other" (EHU V.I.4-5). We discover the causal properties of an object only by observing it in empirical experience, and we assert and believe in particular causal relations only because we've been exposed in experience to events occurring simultaneously or closely in time and place. In fact, we never actually observe causation, only that some "particular objects are constantly conjoined with each other" (EHU IV.I.6, IV.I.10). Therefore, we do not know generalizations about nature a priori, and all statements about facts of the empirical world could conceivably be refuted in experience.

As it turns out, these insights by Hume have influenced much of philosophy of science over the years, and approaches such as EE that focus on empirical experience have taken these points as axiomatic. One conclusion we can draw out here is that statements about nature have no necessity about them. Moreover, it is likely impossible to show by a priori arguments alone that reasoning about, for example, causation or necessary regularities in the world is legitimate. The stance of EE is that we can instead lend weight to the fact that there are many cases of convergence of theories and methods across disciplines in science (Vollmer 2004, p. 209).

We're left with the question of whether we get an accurate picture of the external world by our sensory and reasoning faculties. If experience is our only guide in reasoning about matters of fact, what must we admit if the human mind itself contributes to perception and cognition?

${ }^{2}$ References to Hume come from Ariew \& Watkins 2009, pp. 517-600; EHU stands for $A n$ Enquiry Concerning Human Understanding. 
How do our ideas correspond to what's out in the world? To some extent, Immanuel Kant has provided an answer that accounts for the mind's innate structure, an answer which EE reformulates and adjusts in light of modern evolutionary theory.

Another Approach with Immanuel Kant

In his Critique of Pure Reason, Kant sees himself as ushering in a new era in philosophy. He contends that traditional metaphysics had not made significant progress since the days of the classical Greeks, a fact he believed was due to the wrong approach philosophers had been taking (Kant 1996, B xiv-Xvi) ${ }^{3}$. Metaphysics had been "a mere groping about" (B xv). Kant states that his task in the Critique is to follow the example by Copernicus and "transform the procedure previously followed in metaphysics, by subjecting metaphysics to a complete revolution" (B xxii). In particular, Kant attempts to demonstrate how we can take an inside-out approach to the problem of epistemology and re-orient the observer relative to the object of interest. (Nevermind the fact that Copernicus took the observer from the center to instead revolve around the sun.) Now we no longer are to follow Hume and Locke (and others) in saying that our cognition conforms to experience - that the external world directly provides us with impressions. We must reverse the picture and consider what the cognizer, with their in-built structures and concepts of understanding, does in order to have an appearance of external phenomena (A 85). Objects of experience conform to cognition, and we cannot access anything that lies beyond the appearance (B xvi-Xviii). The profoundly influential idea here was that the mind contributes to the way perception and internal deliberation occur in the understanding.

Kant agrees with Hume and Locke that each legitimate metaphysical concept has a kind of "acquisition story" that explains the concept's empirical origins. He thinks that contentful ideas must arise through sensibility even though the a priori categories do not and cannot have

\footnotetext{
${ }^{3}$ References to Kant follow the unified A/B system of the 1781/1787 editions of the Critique.
} 
an "empirical deduction" (A $28,75,85-86)$. The categories are not determined by anything about the external world itself; and they are more like capacities for organizing your ideas in the unity of your conscious mind (A 80). Yet somehow this is supposed to make certain kinds of inference in science justified, including causal explanations, so that we need not succumb to the skepticism that Hume could not avoid because he could not sanction enough of the right cognitive resources for us to be able to do physics (A 94). Still, Kant's transcendental deduction of the categories is not a purely rationalist thing but is motivated by our encounters with the categories in reasoning experiences (A 86-89).

Kant in the end does not explain where the particular a priori categories and forms of intuition that we have come from. They're simply there, open to analysis, but we cannot explain their presence. And it is this problem that makes Kant relevant to evolutionary epistemology. As it turns out, the two views that there are a priori categories which necessarily dictate the kinds of thoughts we can have and that our mind does not receive raw signals from the sensory organs uninterpreted are common notions in the EE literature (Gontier 2006, p. 4; Riedl 1984, p. 46). In short, EE picks up where Kant left us. EE is the "attempt to explain a priori structures of our knowledge via evolution and to 'dynamize' these structures” (Wuketits 1984, p. 4). The Kantian categories end up having this phylogenetic relativity.

Interestingly, that the categories need not be what they are - that there is no necessity about their actual shape — is consistent with Kant's view that the categories or forms of judgment which are common to all humans may be wholly different for other forms of life (B 152). Other creatures could have awareness of presentations without the unity that consciousness provides and thus without the ability to distinguish between presentations (A 103, B 415). An important distinction, however, is that Kant thinks that, even though humans and animals have sensation, only humans have thought; so reason and understanding are specifically human powers (A 546- 
547). Categories are structures of thought, and animals don't have thought. Also, even though human forms of intuition are open to us for examination, we can never know what forms of intuition animals utilize. This sharp Kantian distinction between humans and animals is discarded in EE. We consider humans to be crucially similar to animals in their genetic and physical makeup, and the physical substrates of thought are essential to any cognitive performance. What is retained from Kant is that structures innate to the mind of the human species (encoded in the DNA) are what make our kind of perception of reality possible.

EE admits that we each have beliefs controlled in part by higher-level mental structures that we may not be able to explain. As Campbell puts it, "we should also accept epistemic humility, recognising the profound indirection and presumptiveness of even our best visual perception and science. We do not know reality in the Dinge an Sich's own language" (1974b, p. 184). But the crucial difference between the epistemic humility that Campbell is recommending here and the (hopeless) inability of ours to explain the Kantian a priori is that Campbell thinks that we need not necessarily stay this way. As science develops, we may always come up with increasingly better explanatory models, for any a priori mental structures are explicable to the extent that they're due to our phylogenetic history.

\section{Naturalized Epistemologies}

Centering around the 1920s and 30s in some parts of Europe and in the 40s and 50s in the United States, a series of philosophers of the Logical Empiricism movement advanced positions overlapping on the premises that epistemology should be based on some form of empiricism and that scientific methods of explanation should reign supreme (Creath 2017). A related aim was to rely solely on mathematics and logic as instruments that supply us with objective measurements and precise structural depictions of the world through "observation sentences" (Gontier 2006, pp. 4-5). The movement is marked by a disdain for traditional philosophy, which was sometimes 
(e.g., by Wittgenstein) pejoratively named "metaphysics." Science was seen as growing out of philosophy and leaving philosophers with nothing empirical to study (Gontier 2006, p. 5-6).

This extreme empiricism facilitated a response, led early on by Willard V. O. Quine (1969), that became the modern naturalistic approach to epistemology. Such an approach is characterized by two primary tenets: humans (and their cognitive faculties) are in nature and interact with nature in ways that can be readily studied in science; and the results of science, including the theories and concepts, can and should be used in epistemology to understand knowledge and justification. Some philosophers who accepted these tenets were drawn to think of traditional epistemology as unnecessary, or confused, or an old "obscurantist" paradigm that didn't help us understand much (Wuketits 1984, pp. 8, 15).

Quine's position is that the progress that had been made and the success achieved in understanding the foundations of science by efforts to ground mathematics in logic, or in logic and set theory, is exemplary (1969, p. 69). But he believed that this (reductive) effort ultimately did not go far enough to "reveal the ground of mathematical knowledge," so "it does not show how mathematical certainty is possible" (p. 70). Yet establishing this certainty, or the impossibility of certainty, is what epistemologists are really interested in. This had previously been the aim of epistemology, and Quine believed that, after Hume proved that laws of nature are not necessary and that reasoning from past to future events is not demonstrably justified, not much progress had been made in epistemology (p. 71). A new approach was needed.

Quine argues that Carnap got close to developing a (non-circular) position, the idea being that we could translate sentences about the world in terms of sense data, logic, and set theory, though it was acknowledged that this wouldn't establish certainty or allow hypotheses of science to be proved logically (p. 74). Yet Carnap's work doesn't complete the picture, and Quine remains disillusioned by traditional attempts to validate science on the grounds of a "first 
philosophy." He points out, in conclusion, that "The stimulation of his sensory receptors is all the evidence anybody has had to go on, ultimately, in arriving at his picture of the world." In other words, all we've got for us to study is what we can observe using the methods of natural science. Quine’s suggestion: "Why not settle for psychology?” (p. 75).

Patricia Churchland's view on the matter is similar to Quine's, and she comes more directly from the field of neuroscience. Churchland believes that philosophers have been abandoning the "grand old paradigm" that emerged from the questions and solutions that first concerned Descartes, Locke, and Hume, and then even the Logical Empiricists (1987, p. 546). She noticed how some of the concepts that arose out of the early modern controversies had been getting less and less serious attention, and that more philosophers were questioning whether it's not "bizarre" to think that "a theory of meaning that has nothing whatever to do with human psychology or neurophysiology can explain the meaningfulness of language and how representational structures relate to the world" (p. 545). Moreover, there are now "remarkable new developments in cognitive neurobiology which encourage us to think that a new and encompassing paradigm is emerging" (p. 546). Churchland points out that our brain and nervous system, as those of other organisms, evolved to enable us to cope with the ecological niche we find ourselves in, not necessarily to enable us to accumulate facts as propositional statements: "Nervous systems are not general-purpose computers" (p. 548). In other words, the scientific evidence doesn't support that our cognition is in some sense pure of biological constraints, the structures and cognitive mechanisms that evolved to help us survive rather than to think abstractly, as was traditionally assumed. Therefore, the epistemological theories we develop concerning information processing should be thoroughly informed by experiment (p. 552).

Churchland is arguing that epistemology had been on the wrong approach to the problem of how we are able to represent reality and that, since it's the nervous system that represents, 
"the fundamental epistemological question can be reformulated thus: How does the brain work?" (p. 546). This question calls for description. It doesn't suggest a way to develop a normative epistemology of how we can form justified beliefs. Yet Churchland does not want to eliminate normativity out of epistemology. Rather, we should begin with adequate definitions of reasoning (for completing computational or representational tasks), and then we can hope to identify what it means to reason well (p. 546).

Franz Wuketits, a key thinker bridging the naturalized approach in epistemology to EE, makes it his goal to avoid "metaphysical obscurantism"- - traditional philosophical ruts in which some thinkers have gotten hopelessly stuck because they've been pursuing the wrong problems. He suggests that we instead embrace a critical approach that saves the objectivity of science without committing us to naive views of realism (Wuketits 1984, p. 15). We must admit that each organism requires a realistic "calculation of the structures of the external world" to be able to cope with the specifics of its environment (p. 14). Organisms are "hypothetical realists" in that they come into the world with a system of hypotheses about their environment - about how the world operates and how to form schemes of reaction. That's all we know for sure because we humans are such organisms, and we should restrict our epistemological questions accordingly. But EE goes beyond non-evolutionary naturalized epistemology by aiming to identify how the evolutionary origin of specific features of our biology affects our thinking and to use this knowledge in answering questions of epistemology. To this end, EE relies on evolutionary theory, so we now turn to the early history of evolution's ripening in the scientific community.

\section{Initial Darwinian Grounds for Evolutionary Explanations}

Before we examine the specific arguments made in the EE literature, it will help to first explain how scientific developments in the mid-19th century were the necessary foundation upon which EE was able to form. I will also show that EE is not simply a Darwinian philosophy, if we 
take the term to mean Darwin's own view of evolution as being due solely to chance variations and natural selection. There have been over the years several accounts of mechanisms in evolution - how and why evolution occurs. The view of evolution's mechanisms that one takes will dictate the way epistemology can be evolutionary.

Although early in the 19th century some people had already accepted organic evolution as a type of global unfolding that governs the universe, it was Darwin's Origin of Species in 1859 that "changed evolution from fanciful speculation to established fact" (Ruse 1998, p. 2). Darwin's huge contribution to science was that natural selection operating on random variation is what drives evolutionary change. So long as there is variation across the generations of a species, selective pressures will result in adaptations and diversity in nature (Ruse 1998, p. 16). There remained no need to invoke teleological doctrines to explain even complex and sophisticated natural phenomena. Furthermore, Darwin outlined the cornerstones of what became the field of evolutionary psychology. In his later books he shows both that humans stem from the animal kingdom and that human mental abilities evolved naturally. As Ruse puts it, "If you take Darwin seriously ... then the special status of Homo sapiens is gone for ever" (1998, p. 104).

Contemporaneously with Darwin, Herbert Spencer was known for applying insights of natural selection to psychology and sociology, and his psychology was itself sometimes seen as offering parts of an epistemology (Wuketits 1990, pp. 1-2). Spencer was kind of forerunner of EE, drawing links between the evolutionary development of organisms and the development of culture (pp. 35-36). Unlike Spencer's, however, Darwin's work showing that natural selection is the primary mechanism behind the evolution of human psychology was "founded on a mass of empirical evidence and did not lack scientific rigour" (pp. 1-2). Still, Darwin recognized Spencer's contributions and wrote that "Psychology will be securely based on the foundation already well laid by Mr. Herbert Spencer, that of the necessary acquirement of each mental 
power and capacity by gradation" (Darwin 1875, p. 428). The attempt to explain how and why we think the way we do using naturalistic concepts alone is therefore nothing new.

Works by proto-evolutionary epistemologists — which besides Spencer included Ernest Haeckel, Georg Simmel, and others_-provided the basis for the premise of EE that human cognition is biologically constrained and explainable partly in evolutionary terms (Campbell 1974, pp. 437-440; Wuketits 1990, p. 2). With the observation that the human mind evolved just like all other organs, it seemed fitting to some naturalistically-inclined philosophers to expand on this science to address problems in epistemology.

\section{The Stance of EE and a few Prominent Views}

\section{Early EE Work: Evolution as a Cognition Process}

Evolutionary epistemology takes inspiration from and combines naturalized epistemology with the explanatory power of evolutionary theory. In fact, EE may be seen as "a branch within" naturalized epistemology (Gontier 2006, p. 9). During the 1970s and early 1980s, EE relied heavily on the Neo-Darwinist understanding of organic evolution, defined as the synthesis of Darwinism with modern genetics. As we'll see later, alternative conceptions of the mechanisms of evolution have morphed EE over the years.

The first sketch of EE came in a chapter by Donald Campbell in a book on Karl Popper's lifelong philosophy (1974). The chapter, whose title named this emerging field of "Evolutionary Epistemology," lays out the principles of the EE approach: it's about having a non-reductionist framework that is informed by and compatible with what we know about biological and social evolution. Campbell introduces both the ideas that "evolution-even in its biological aspects-is a knowledge process" and that the natural selection paradigm "can be generalized to other epistemic activities" such as science (p. 413). His is therefore essentially a natural selection epistemology as he aims here to take Popper's philosophy of science to its conclusions. Although 
Popper was interested in the growth of conceptual knowledge by individuals and collective knowledge by societies, Campbell applies the natural selection model to understand "epistemic" structures of all life-from the rudimentary paramecium to the great Einstein (pp. 418-422). His famous "blind-variation-and-selective-retention" scheme is meant to model the process that's fundamental to all increases in knowledge (p. 421). By this process organisms acquire fit to their environment, and it's the process Campbell believes is the emerging paradigm for explaining teleological achievements at all levels of organic phenomena. Variation is blind in that the production of variations is not informed by which variations will be more fitting; the process works independently of any environmental conditions or survival needs of the organism (pp. 421-422). There has, therefore, never been a "transfusion of knowledge" or of mechanisms of knowing or of fundamental truths "from the outside" (p. 413). Moreover, skepticism about perception and cognition - including what we find in the ancient Greek skepticism of, for example, Arcesilaus and Sextus Empiricus - is compatible with the evolutionary approach to epistemology (Campbell 1987, pp. 165-166).

Campbell's "evolution is a knowledge process" metaphor has turned out to be influential in the EE literature that followed. To Campbell, knowledge is not just about believing true or justified propositions. An animal's instinctual behavior shows "wisdom" about the environment and is a form of knowledge. The bacterium's movements exhibit knowledge, and "The shape of a horse's hoof certainly expresses 'knowledge' of the steppe in a very odd and partial language, and in an end product mixed with 'knowledge' of other contingencies" (p. 447). The upshot is that our cognitive processes (and those of any organism) are imperfect, that our knowledge of the external world indirect, and that our scientific knowledge is at best proximate (p. 437). You can't accept this and remain a "naive realist." We have no reason to think that we can attain perfect knowledge of anything or have absolute certainties. 
Gontier adopts part of Campbell's useful approach to say that each organism is a system of knowledge that represents and contains information about its external world-whether or not the organism uses language or has a brain or sensory organs (2006, p. 10). Although evolution involves undirected hypotheses ("in the Popperian sense of the word") about organisms and their needs in the environment, a reliable concurrent process tests each hypothesis: a hypothesis is confirmed by an organism's marginally better survival, or it is falsified when the novelty turns out to be maladaptive (p. 10). Therefore, concludes Gontier, by studying an organism we can learn about the conditions within which it evolved.

$\mathrm{EE}$ is premised on the idea that there are objectively real regularities and invariants which make cognition possible. Vollmer (1984) admits as an empirical fact that there is "agreement" between the world and our knowledge of it, and he writes that the task of EE is to explain why there is this far-reaching agreement "between objective structures (of the real world outside) and subjective structures (of our knowledge about this world)" (p. 75). The answer given by EE is that it's not a coincidence or due to pre-established harmony, as many people had supposed. The answer is, of course, that our cognitive mechanisms are results of biological evolution and cohere with "objective structures" of the world because they're adaptations - "they are partially isomorphic to this world because otherwise we could not have survived" (p. 75). But we must not overstate this apparent fact. Biological organs don't represent or portray external conditions as some have said (e.g., Lorenz); an organ may not even mirror an aspect of the world, for it is a different thing from the conditions within which it evolves: "The sun and the eye have nothing in common" (p. 71). Yet organs that are retained over evolutionary time at least hint at what must be true about the environment. For example, by studying a particular tool we can infer what jobs it's suited for (e.g., a torch couldn't be used for unscrewing a bolt). It is only in this limited sense that we can say that an organism represents or mirrors its environment. The fact that our sense 
organs are terrifically useful for our interactions with the environment does not by itself mean that we get a true picture of reality (p. 72). Vollmer thinks Kant rightly detected that the knowing subject's innate traits have an important role in the formation of knowledge but exaggerated this fact (p. 71). On the other hand, because the knowing subject's own contribution to knowledge of the world matters, the simple claim that cognition mirrors the outside world is inaccurate. This leads us into the topic of feedback mechanisms and top-downward causation. More Recent Developments: Systems Theory

Up until the last couple decades of the 20th century, Darwinian natural selection was emphasized as the sole or at least the primary explanation of evolution. Yet it is just one theory explaining evolution and not the only plausible one; other mechanisms of evolution have been debated throughout the history of evolutionary theory (Gontier 2006, p. 2). Since the early 1980s, a number of scientifically informed philosophers have drawn from sophisticated, breakthrough models of evolutionary change based on insights from systems theory and nonlinear dynamics. Dynamic systems theory appears to provide the currently dominant approach within EE.

One motivation for the new approach to EE is the desire to explain those elaborate and complex patterns of fit between organisms, or social groups, and their environment about which teleological explanations (or even explanations stirring final-causes talk) have gotten attention. A leading early figure of this new EE program was Rupert Riedl, who developed key concepts of the systems-theoretical approach to biology and epistemology (Riedl 1984, pp. 38-39). In his scientific career, Riedl was interested in explaining the great harmony between (morphological) structures in organisms and their external conditions. After extensive research, he concluded that "to examine history for regularities, a consistent theory is needed" but that such a theory did not yet exist (p. 36). He was not convinced that plain old Darwinism could sufficiently explain the fit between organisms and their environment. Some apparent adaptations appear just too fitting, 
adaptations that needed a more sophisticated theory of the mechanisms of evolution.

In Riedl's view, nature exhibits nested hierarchies of order, a fact that researchers working in traditional Darwinian natural selection theory had overlooked, though Campbell had discussed this idea without taking it to its scientific conclusions. Riedl argues that there is a kind of "correspondence between cognitive and natural order" that cannot be explained as due to chance-_"One had to be the cause of the other" (p. 39). It concerned Riedl early in his research days that it was generally accepted that nature, but not cognitive order, was explicable naturalistically. He became drawn to the possibility that cognitive order is "a selection product of natural order" so that hierarchy in nature is not a mere thought projection by us (pp. 39-40).

From his scientific research, Riedl found that humans possess a "system of hypotheses" innately - that is, genetically stabilized patterns of cognition, or "hereditary decision aids of living systems" (pp. 40-44, 46). Riedl maintains that this system of hypotheses evolved in its particular way because of corresponding realities in the world. This indicates that at least the cognition patterns that rely on these hypotheses are directly grounded in and selectively vetted by reality, which serves to partly justify these cognition patterns. The first of these hypotheses is that the world operates in a way that is predictable in a probabilistic sense, so we have an "innate ability to count on probabilities" (p. 42). Not that we consciously evaluate probabilities in a rigorous way when our well-being depends on it-it's more fundamental than that. We notice regularities, make predictions, and note when our predictions are confirmed — and all this mostly unconsciously, including when our livelihood depends on it. This ability allowed pre-human species to learn and develop habits to assist them with their own living conditions. So the ability for an organism to learn probabilistic regularities during its lifetime and to infer based on this knowledge, a hugely life-preserving capacity, is explained as having evolved in accordance with a fact of natural reality. 
An interesting analogue is found in the accounts of human thinking by both Bacon and Hume and even Kant. Each stated the fact that humans tend to notice patterns and associations, or to rely on the category of Modality or "problematic" thinking. But these pre-evolutionarytheory accounts don't explain naturalistically why cognition in the human species came to have these particular traits.

Consider also the capacity for causal inference: noticing patterns when one kind of event follows another kind and inferring that the first causes the second. This is, in Riedl's view, an innate ratiomorphic hypothesis (pp. 43-44). We often naturally and automatically jump to conclusions about two coinciding events as being causally related, sometimes after just one coincidence (p. 44). Kaspar suggests that this ability may have as a precondition the ability to simply learn a "certain sequence of occurrences" (1984, p. 61). After repeated, and especially frequent, coincidences of events in close succession, animals of many species can be conditioned to react a certain way - they only need to bring up from memory, unconsciously, that the two situations are related a particular way.

Hume noticed that people rely on the relation of cause and effect in tying ideas together and listed this pattern of thinking among the three Principles of Association. People make causal inferences because of custom and habit, which may be so strong and influential to our thinking that we may often not notice their effect on us (EHU IV.1.8, V.1.2-5). Of course, this does not invalidate causal inference; it doesn't suggest that causal inference is unjustified. But, we may ask, does this account complete the picture? For Hume's purposes, we might not need, for example, to inquiry into the underlying biological or neurological causes. Yet for those seeking a deeper naturalistic answer, it seems that it'd be necessary to draw on a theory, such as evolution, for reverse-engineering the mind. As Riedl argues, it was work in evolutionary systems theory, applied to cognition in the 1970s and 1980s by researchers including himself, that gave scientists 
a powerful explanatory model, with evidential backing, of why humans and some animals exhibit patterns of causal inference.

Another information-gaining process that humans exhibit is to ignore "the dissimilar in the similar" (Riedl 1984, p. 43). This ratiomorphic hypothesis reflects the reality that many things in the world resemble other things even though no two things are perfectly identical. For example, no two fig trees, or rivers, or clouds are identical. Yet somehow we are able to recognize two different things as being relevantly similar-we abstract away from differences when we need to classify things in the world. Importantly, this is not a uniquely human ability: many animals (i.e., primates) exhibit this ability to varying degrees (p. 43). This "performance of cognition" is also what enables distinguishing between different species (for example one's own from predators) — and it is what makes Gestalt possible (Kaspar 1984, pp. 55, 59). It's thus an important foundational ability for developing basic heuristics in learned schemes of reaction and even communication.

A fourth principle of cognitive order that Riedl identifies reflects the qualitatively different natures of effects in a hierarchy based on whether a higher element in the hierarchy is acting on its lower elements or, on the other hand, a lower element is affecting a higher element (p. 44). The direction of the causation influences how we perceive the relationship between the objects, and for this reason "the forces and final causes appear to us as distinct qualities" (p. 43). We tend to see nested, component forces and mechanisms as contributing to a bigger structure in a meaningful way, and we are naturally drawn to emphasize purpose in many explanations. Humans and other primates exhibit this tendency to seek out the aims or purposes of objects and events - humans in the most sophisticated way, of course. Riedl illustrates this concept with the example of the bicep muscle in the human body: we can explain its internals in a purely biological way (the physics and chemistry), but we can't help but to also offer a teleological 
explanation in terms of the muscle's role in the body (p. 44). We naturally perceive that the physical characteristics of the bicep successfully make it into a muscle that bridges the shoulder joint and elbow — and we tend to think of the muscle as being there for this purpose.

Today, the guiding explanatory axiom in the EE paradigm is that of a dynamic process of feedback-driven evolution. Because everything is natural — there are no Baconian "Ideas of the divine mind"- - we can explain both the human with reference to the external world and the external world with reference to human cognition. It's a powerful paradigm, and it makes sense only if there is some kind of reality existing independently of living systems, a reality with which our ratiomorphic apparatus evolved. For example, we're able to learn because there is order in the world (Kaspar 1984, p. 57). Living systems are not simply contained in "external conditions" and do not evolve for independently changing conditions. Rather, living things (through their phylogenetic history) shape what is external to them, their ecological niche, what is accessible via the senses. "Schemes of reaction" are developed in tandem with what becomes accessible via the senses, which is all that the organism with its biological constraints could possibly experience (Kaspar 1984, p. 63; Wuketits 2006, p. 43). The a priori categories in our biology, therefore, are the fundamental preconditions of our conscious reason, so "they are not to be justified by reason alone" (Riedl 1984, p. 46). On this view, reason, whatever that is, is therefore a naturally explicable thing to the extent that it's explicable at all.

Wuketits has been another leading thinker bringing grounding to EE with systems theory, which he believes is superior to a traditional adaptationist approach because it accounts for how organisms partake in a feedback loop that influences their evolution. The adaptationist approach made the external environment the center and frame of reference within which organisms evolve. In contrast, Wuketits argues that organisms are not simply molded by their environment. They don't merely adapt. Innate cognitive structures produce a coherent scheme of external reality for 
organisms to shape their external conditions and constrain their evolution (1990, p. 153).

Wuketits thus takes what he calls an organism-centric stance in thinking about evolution. He argues, moreover, that the fact that organisms constrain their environment is true at both levels of evolution studied in EE: in the biological evolution of cognitive structures and mechanisms, and obviously in cultural evolution where humans have conscious teleological intentions (p. 153).

Gontier calls the systems theory position a "New EE" which fully embraces the idea that the organism participates in the evolutionary learning process, discarding the distinction between ontogenesis and phylogenesis (2006, pp. 11-12). Gontier is motivated partly by how biologists had since the mid-20th-century been identifying how natural selection operates at levels other than just at the phenotypic, or with other units of selection. She writes that natural selection of phenotypes is not synonymous with evolution because this selection is but one explanation of evolution (p. 12). Alternative explanations have the organism conceptually at the center, taking part in and influencing its own evolution. It helps to view organisms as "autocatalytic systems" to the extent that "they are able to self-maintain due to the inner mechanisms they develop in order to survive" (p. 14). Therefore, adaptation is not to imply a plain adaptation of an organism to the external world.

The concept of self-organization, though for most of scientific history since Darwin seen as too vitalistic or suggestive of intelligent design, has come back with rigorous formulations based on extensive scientific grounding and fully naturalistic. Wuketits and others have argued convincingly for sophisticated naturalistic accounts of some kinds of complex phenomena. The idea is that living systems are hierarchically organized and "open" at various levels of biological order in the sense that internal systems interact with the other levels and constrain the form and extent of the organism's adaptability (Wuketits 2006, p. 38). There is ongoing feedback and causation directed both up and down the hierarchy (c.f. Campbell 1974b). Kaspar writes that, 
although classical thermodynamics may seem to prohibit the self-ordering of natural systems, in fact evolution is about open systems that need to be taken with the context of their surroundings (Kaspar 1984, p. 51). At every level of complexity in organic structures, selection is active in "testing" sub-components within their direct surroundings, or, more precisely, within the "next subordinated system" (p. 53). Therefore, to understand large complex systems, we need to see each nested hierarchy as being selected for within its own immediate context—not as selected to contribute to the organism viewed at the broadest level. There are evolutionary feedback cycles at every level of hierarchically organized systems (pp. 51-53). Each structure in a biological system is adapted to one part of the environment, so "organisms do not represent the world "in itself', but only in the pragmatic sense, obtain 'knowledge' about conditions which are relevant in a concrete situation" (p. 54). Cognition-gaining is driven by the same principle of selforganization that drives the development of nervous systems (p. 55).

Drawing on such theoretical models is nothing new to biology. Weber and Depew (1996) demonstrate how, from the earliest days of work in evolutionary theory, biologists have been assisted by models in physics (especially dynamics) for clarifying and quantifying concepts. There has been "a vital and vitalizing connection between Darwinism and dynamics," and even though Darwinian research has always had some conception of natural selection at its core, the precise formulation of selection has been adjusted several times (pp. 33-34). Weber and Depew report that a new series of natural selection theories are taking account of growth in the field of nonlinear dynamics, which studies and explains self-organization in complex systems (p. 34). Self-organization as conceived of by the authors is evident in genetic development, where it is not just chance and natural selection in operation (p. 38). The selection that occurs at this level obviously does not have organisms as the unit of selection, a fact which calls for a more general formulation of natural selection that can apply to organisms (in the study of phylogenesis) as 
well as to genes (in the study of both phylogenesis and ontogenesis) (p. 39). The problem is that Darwinian evolution, even in the Modern Synthesis, did not anticipate the work that would be done with the very small (genes) and the very large (phyla), so plain Darwinian selectionism, though valid for a certain range of phenomena, does not explain evolution outside of this range (pp. 40-41). We should view natural selection and self-organization as "two aspects of a single evolutionary process," so this does not threaten the status of Darwinian natural selection as crucial to evolution (p. 45). The authors aim to have their model of evolution explain, in a fully naturalistic way, much phenomena that had hitherto attracted teleological concepts (p. 57).

The point of this overview of modern EE is to show that EE goes beyond extending the traditional Darwinian model of evolution: it questions old models and contributes to a framework that is based on interdisciplinary scientific theories, thereby feeding back to the science. Changes in culture have been taken into the explanatory scope of these theories. There's a long history of attempts to explain cultural change and belief systems; we turn now to this topic and view it through the lens of evolutionary epistemology.

Another Program in EE: Scientific Development is Analogous to Biological Evolution

The other program within EE developed mostly independently of epistemologies of cognition and is about describing cultural change and theory change (and even methodology change) in science; call it EET. The concern in EET is to construct a metatheory of rational knowledge in terms of evolution, or with a more abstract selectionist theory of trial-and-errorelimination (Campbell 1974, pp. 413, 416; Wuketits 1990, p. 5). In the latter half of the 19th century, philosophers including Ernst Mach, Alexander Bain, Stanley Jevons, Paul Souriau, William James, and C. S. Pierce began to suggest that our belief-forming processes are not simply cumulative and directly arising from experience but are a series of guesses and corrections (Campbell 1974, pp. 427-429). Most of these thinkers were more or less acquainted 
with evolutionary theory, though it's not clear whether they were directly inspired by it. They believed that we never find the absolute truth about anything in nature but only arrive at increasingly better approximations. Knowledge-gaining was seen as the process of making blind or anticipatory guesses and then pitting them against other candidate guesses to see which best stood the scientific trials and is retained.

In the 20th century, the leading proponent of EET was Karl Popper, who agreed with the aforementioned 19th century thinkers that we are fallible yet urged that this does not imply skepticism or relativism. Our knowledge can grow and progress. He famously described science as a series of "conjectures and refutations." In a correspondingly named book, his theory of (the growth of) knowledge is based on the simple overarching premise that we can learn from our mistakes. Although our knowledge (including scientific knowledge) advances by way of unjustifiable guesses or conjectures, and although we have no way to deduce theories or even infer inductively what theory must be correct given the evidence, we can refute conjectures in a more rational and evidence-based way. Each tentative solution to a problem must be put to severe testing. We rely on empirical observations and critical argument to test and eliminate mistaken hypotheses. We gain some knowledge when we refute a proposed conjecture, but we can never prove a hypothesis or even demonstrate that it's probably true (Popper 2002, p. xi). A hypothesis or a solution to a problem is scientific only insofar as it is testable.

Popper asks, "But what, then, are the sources of our knowledge?" His answer is that "there are all kinds of sources of our knowledge; but none has authority" (p. 32). Popper finds it fruitful to ask instead of "what source of knowledge is best?" the better question of how we can "detect and eliminate error" given that pure and certain sources of knowledge don't exist (pp. 33-34). So, on this view, anyone can conjecture anything and happen to be correct, and the way we should approach any claim to truth is by testing it just as critically as every other conjecture. 
The significant contribution to this topic by Popper was, says Donald Campbell, not another answer to the questions Hume dealt with—rather, Popper changed focus and re-centered the epistemological problem: "The central requirement becomes an epistemology capable of handling expansions of knowledge, breakouts from the limits of prior wisdom, scientific discovery" (p. 417). In other words, the central efforts are the study of reliable learning and the criteria for accepting or to rejecting theories. Interestingly enough, though, Popper never thought of his philosophy of science as an "evolutionary epistemology" until Donald Campbell called it so in that (1974) chapter in a book on Popper's philosophy.

Campbell builds on Hume's and Popper's idea that our reasoning and perceiving faculties do not give us ground for certainty about scientific laws having anything like absolute truth. Our faculties have evolved to help us survive, and we have only a partial grasp of the world that's out there (pp. 414-415, 437). He adds that the evolutionary approach to epistemology gives up the traditional effort to hold back all knowledge until we establish that knowledge is possible or to suspend sense data until there are indubitable grounds for its validity (p. 418). We have no proven modes of knowing without presuppositions, and we can't refute solipsism—but, he says, those aren't the interesting problems. The "problem of knowledge" is instead about "truth claims descriptive of a more than now-phenomenal world" (p. 418). We should explain, for example, when we can postulate unobservable entities or laws of nature. We must not expect independent justification of a process of theory construction, and we accordingly need not hesitate to accept a belief just because it lacks inductive support—we must apply it to our problems and see if it's a solution (p. 419). Campbell thus thinks that Popper's definition of knowledge should encourage us to try out theories and tentatively accept only those that stand as yet not refuted.

Franz Wuketits is noteworthy here too. Wuketits asks a few questions that had been mostly overlooked in the EE literature, such as why exactly can we liken EET to EEM? Or to 
what extent is the one distinct from the other? Wuketits thinks EE is relevant to explaining theory change because EEM and EET overlap on the premises that "evolution is to be taken as a basis for cognition processes of all kinds" and that evolution is itself a cognition and learning process (1990, pp. 8, 152). A continuum of information-processing levels spans all forms of life. At the genetic level information is transmitted only by inheritance; at the preconscious cognition level, many animal species and humans acquire information from signals by the external world and can make small adjustments to their behavior accordingly; and at the rational knowledge level, humans are able to take advantage of intellectual information and pass it to other humans exosomatically, such as through writing (p. 55). Individual learning is more efficient and rapid because it is not tied down to any particular biological subsystem other than the neuro-cognitive structures that create a plane for information processing above the biological substrates. Humans and some animals have individual learning abilities that enable them to transgress hereditary instincts (p. 65). However, that the ability for intellectual information processing in humans is a product of evolution does not by itself imply that the process by which knowledge develops (and science progresses) in human culture is like the process of organic evolution. Nor is scientific inquiry a direct result of natural biological processes. Nor is EET a logical progression of EEM. Wuketits adds that the key aspect differentiating scientific change from organic evolution is that intellectual information is transmitted "via exosomatic structures" (p. 166). So if the two processes are in some ways analogous, this fact is entirely contingent.

Popper, however, would not agree on this last point. In Conjectures and Refutations, he writes that all learning is done by way of unjustifiable guesses or conjectures, controlled by criticism and attempted refutations. Any tentative solution to any problem is to be put to severe testing. We gain some knowledge when we refute a proposed conjecture. Campbell explains, also, that in Clouds and Clocks Popper sees the natural selection paradigm as "the universal 
nonteleological explanation of teleological achievements, of ends-guided processes, of 'fit'" (Campbell 1974, p. 420). As we saw earlier, a counterpart theory of Campbell's is the "blindvariation-and-selective-retention" scheme (p. 421). This is, in other words, a universal law of learning. Yet, even though Popper writes that "The method of trial and error is applied not only by Einstein but, in a more dogmatic fashion, by the amoeba also," he is ready to admit that "The method of trial and error is not, of course, simply identical with the scientific or critical approach — with the method of conjecture and refutation" (Popper 2002, p. 68). The difference is that the scientist, but not the amoeba, takes "a critical and constructive attitude towards errors; errors which the scientist consciously and cautiously tries to uncover in order to refute his theories with searching arguments, including appeals to the most severe experimental tests which his theories and his ingenuity permit him to design" (p. 68).

Should each project, EEM and EET, be treated separately in professional research, to avoid giving the impression that certain scientific findings directly say something about what has traditionally been the focus of epistemology? Many biologists and psychologists present their scientific work as epistemology (e.g., Campbell, Riedl, etc.). Are justification and the status of knowledge matters of science as well as of philosophy? One answer is that the evolutionary study of epistemological or knowing mechanisms is within the domain of science while the nature of science itself and of scientific theory change is the domain of philosophy. Or we may think of EE as being both a biological (and thus scientific) meta-theory as well as a philosophical approach to epistemology because of its normative stance concerning the proper way to answer questions about the justifiability of our learning procedures. In any case, EE thus goes "beyond traditional disciplinary boundaries" (Wuketits 1990, p. 4). To the extent that it is shaped by science, it lacks independent philosophical motivations beyond the aim to have a unified theory of all knowledge and learning. Whether such a theory is possible is, however, another question. 


\section{Critiques and Limitations}

There has, unsurprisingly, been reflection on and critique of the evolutionary approach to epistemology. The approach certainly has its limitations, and it's been argued that some of the conclusions drawn using concepts of EE, especially about scientific development, are not sound. Having established that EEM and EET are crucially distinct, we discuss now the critiques and limitations of each program separately.

\section{Critiques and Limitations of EEM}

The first kind of criticism pivots around the uneasiness with which EE is often situated in the balance between being pure philosophy of a top-downward approach or being plain natural science. Many thinkers are not explicit about whether their theory has philosophical aims or is meant only to explain certain concrete findings of science. Some label EEM as both a scientific and a philosophical position (e.g., Vollmer 1984; Gontier 2006); some say it answers scientific questions while suggesting philosophical points on topics like morality and ontology (Wuketits 1990). Plotkin thinks this ambiguity in the purpose of EE makes it unscientific (it isn't biology), a situation from which, he says, EE can be rescued only if it comes to have its own scientific basis (1987, pp. 295-297). At the time, Plotkin saw EE as not sufficiently grounded in science though meant to address the problem of knowledge by science. The difference, he says, between philosophy and science has to do with "the accessibility of the product of analysis, of a theory, to empirical test," where accessibility is "judged in terms of the intention of disciplining a theory by empirical testing” (p. 296). Plotkin argues that whether cognitive processes are evolutionary processes is a contentious, scientific question that "will not be solved by analysis alone" (p. 302). To continue to be seen as at least in part scientific, EE must contribute a model that integrates at least genetics, epigenetics, and cognition to account for how a set of adaptations can exhibit "knowing" about its environment (p. 309). But if EE is transformed into a scientific theory, what 
philosophical relevance could it then have?

Löw refines this point among the objections he raises against EE. He argues that, though EE is usually taken to be a scientific theory, it is in fact only a "philosophical proposal for the interpretation of certain findings" (1984, p. 209). The problem is with the way concepts such as "life" and "knowledge" get defined; the arbitrary definitions are intended to make it possible to explain, naturalistically, the emergence of life, cognition, knowledge, etc. (p. 210). Yet the resultant explanations fail to amount to being scientific precisely because of these definitions. EE first is claimed to account for knowledge like any other epistemology and to do so using science, yet it requires conceptual shifts that are foreign to science. It turns out to not help biology at all. The definition of knowledge in EE — in which are included the fitness of structures in unicellular organisms, simulation of external conditions by physical organs, and of course conceptual representation of information - has no empirical basis and makes the entire program circular. Making knowledge multi-level this way is "good for nothing" because this only introduces equivocation to permit the higher levels of knowledge in life to emerge from the lower (pp. 211212). So the concepts on which EE integrally relies are defined in a way that end up making the agenda of EE meaningless.

The start of an answer to this objection could be to admit that EE is not a scientific theory after all and that its usefulness to science per se is irrelevant. Therefore, Löw's objection is not clearly problematic to EE if we take EE to be only a scientifically informed naturalized epistemology (Gontier 2006). It would be the task of scientists to keep EE in check.

Another critique concerns the question of whether, in an EE, we can say anything about the likelihood that our beliefs are true given that evolution is concerned only with fitting living organisms better to their environments. If we agree that the nervous system evolved solely "to get the body parts where they should be in order that the organism may survive," then it seems 
we must agree with Churchland that "Truth, whatever that is, definitely takes the hindmost" (Churchland 1987, pp. 548-549). It's prima facie obvious: evolution is an undirected process that optimizes for survival, not for true beliefs — or any beliefs for that matter. What a living being thinks (philosophically) makes no difference in life-critical situations where some immediate response needs to be made. As Wuketits explains, humans remain constrained by their "innate teaching mechanisms," which were "selected in prehistoric times for survival's sake in a world which differs greatly from our world of today" $(1984$, p. 22). So why think that our epistemic structures ascertain actually true beliefs? If evolutionary science cannot answer this question, then EE falls flat on its face without helping resolve the problem of epistemology. The answer is probably that we need to distinguish between different kinds of belief: only some are about immediate external conditions, and these beliefs must be formed sufficiently reliably to aid our survival. Other beliefs — conceptual or theoretical ones- that we hold don't matter for survival, so whether beliefs of this class are formed reliably is something we can address without necessarily giving much weight to the fact that our epistemic structures evolved to enable us to better cope with survival conditions. That the same or related epistemic structures make abstract thought, an emergent capacity (Wuketits 1990, pp. 196-197), possible is therefore mostly irrelevant. In other words, it's not entirely true that cognitive structures evolved for survival's sake. There has evolved (at least in humans) a mental plane for cognitive performance that is not controlled by its biological substrates. So informational reasoning is an emergent capacity of the brain that is, in a sense, partly detached from its neurological basis. The particular ideas we form are not due to or explicable by our phylogenetic history. Cognitive processes have evolved because genes acting alone are limited in the way they can equip phenotypes to deal with the environment, and behaviors that are due to cognitive processes cannot be reduced to genetically endowed differences (Plotkin 1987, p. 301). Thus cognitive processes allow semi- 
autonomous decision-making for individuals within their lifetime. Even if much of our conscious

life is constrained by our biology, not all of our cognitive capacities evolved to only assist us in forming useful "schemes of reaction."

\section{Critiques and Limitations of EET}

About the EET program (studying the evolutionary nature of theories), Thagard expresses various points of criticism. Viewing EET as relying on analogies from theories of biology, he argues that "similarities between biological and scientific development are superficial" and that non-Darwinian approaches to "historical epistemology" are superior (Thagard 1980, p. 187). The difference he emphasizes is that an essential part of naturalistic evolution is blind variation, which means that variations arise without regard to the specific needs of the individual or species and are not corrections of previous variations, yet scientific developments result from concern with specific recognized problems and are intended by scientists to solve the problems (p. 188).

Science proceeds by careful abductive inference as hypotheses are proposed to explain puzzling phenomena, and, importantly, it can't be that all or most scientific hypotheses are invented randomly or blindly, for that wouldn't account for the obvious rate of progress in science (pp. 188-189). Also, as Kuhn (2012) points out, the rate at which novel scientific theories and concepts are produced in a discipline depends on the degree to which a scientific paradigm of the relevant scientists is in crisis (when the paradigm is close to being replaced). Yet the rate of evolutionary innovation does not thus depend on environmental stresses (p. 190).

On the selection side of evolution, there too is a difference between biological evolution and theory evolution in science. It is intentional agents who select theories according to global scientific goals of "finding solutions to problems, explaining facts, achieving simplicity, making accurate predictions, and so on"-all of which depends in part on (subjective) motivations of scientists (Thagard 1980, pp. 190-191). In contrast, natural selection selects in a way that's 
pragmatic, without having underlying motivations, for particular local environments, and there's no way an organism can be inherently "fit" (pp. 190-191). Though in the evolution of organisms, fit is a matter of the environmental context, in science we assume that certain universal principles should be used to evaluated hypotheses.

This criticism by Thagard is insightful and correct if EET in fact extends by analogy from evolutionary biology to explain increases in theoretical knowledge. As we'll see later, however, another way to understand the evolution of theories is by making it just a case of a more general selectionist model. If explanation of theory change is to be seen as evolutionary, it appears that such a stance is viable only under such an abstract model of evolution. This may explain why Popper did not himself describe science as a process of Darwinian evolution. But Akeroyd (2004) and Worrall (1995) have argued that key points in Popper's approach were based on analogies between the way biological species and scientific theories evolve.

While Thagard focuses on the causes and mechanisms of evolution, Michael Ruse attacks "traditional" Darwinian evolutionary epistemology (as he calls it) also at the level of the path of evolution. Ruse is concerned with late-19th and early-20th century evolutionary epistemologies that are based on analogy from biological evolution, and he says they all fail (p. 31). Focusing on scientific knowledge, he thinks this traditional EE approach is "beyond repair" (pp. 31-32).

Ruse first makes the same point as Thagard (1980) about the conscious directedness of science but not of organic change (1998, pp. 56-57). The sources of variation in the two areas are too different in kind. Variations in organic evolution are totally opportunistic. Particular mutations do not occur because of certain environmental pressures (p. 54). Yet in scientific work, scientists draw out discoveries "to do the job properly" - to explain observed phenomena in a way they think is consistent with what is really happening in the world (p. 57). Scientists want to be correct; they direct their work toward what they perceive to be the truth. 
Furthermore, there is the question of whether there is a sense in which evolution exhibits progress. Ruse actually admits that science changes over time in evolution-like ways, more or less the way Toulmin describes it: theories change gradually, always building on existing theories, and any two theories about a set of phenomena will have similarities and differences (pp. 48-49). Yet there is a crucial difference between the path of organic evolution and the path of scientific theory change: "organic evolution is really not progressive, whereas scientific evolution is apparently progressive" (p. 49). If evolution has no teleological aim, then it does not result in progress per se. Compare a lion to a human. Which is better evolved? The question doesn't make sense, for it's all relative to the environmental context. In some ways the lion is tremendously more adapted and more capable — more fit — while in other ways humans are incomparably superior. Ruse adds that, in Darwinian evolution, an important theme is the "fanning out, like branches of a tree," of species; this is why progression doesn't make much sense (p. 51). In science, however, we sometimes see theories from different disciplines coming together, hybridizing, showing consilience and thereby leading toward what is often considered understanding of objective reality. It makes sense to speak of scientific progress (p. 51).

Ruse downplays this objection to EET by adding that organic evolution "shows a quasiprogress: microbe to man" (p. 49). Organic evolution includes the emergence of increasingly more sophisticated organisms. At the same time, there's no reason to think of science as being progressive in some absolute way. "Scientific progress is essentially illusory" in the sense that we're always going to be coming up with ever better scientific theories and concepts (p. 50). New scientific theories tend to be better approximations than earlier theories though never perfect—like biological organisms, always becoming more adapted but never so adapted that no improvement is possible. Just as organisms survive because they "work better" than others, theories continue to exist insofar as they serve their respective scientific community (p. 50). 
Andersson (2008) stresses that explanations of cultural evolution by means of blind variation and selection alone are not sufficient (pp. 230-232, 241). Selection isn't a good theory for much of human knowledge progress because the way humans gain knowledge makes it partly feasible to predict which belief or theory is likely to be more accurate, which isn't something we'd expect if theory innovation were blind like genetic mutation (p. 231). Of course, a scientific explanation of the possibility of such prescience must not invoke anything like miracles (p. 232); we presume that something natural explains this fact-perhaps there are real regularities in the world and we can get good at predicting unobvious regularities. Since organic evolution is assumed to not include ends-guided mutations, we can therefore at least conclude that this is yet another point of distinction between scientific theory change and evolutionary change.

There are, therefore, various objections to both EEM and EET. Although future work may resolve some of these problems, another kind of objection concerns the very nature of EE and the aims for which it has been promoted. More precisely, if EE is a descriptive and not a normative epistemology (Campbell 1987, p. 165), a question arises concerning how and if EE relates to traditional epistemological approaches.

\section{Does EE Compete with or Supersede Traditional Epistemology?}

Have the leading thinkers in EE intended to do away with traditional epistemology? It's not perfectly clear if that's the dominant position, but there are at least a few thinkers on either side of the question. Some view EE as being in direct competition with TE, and some view EE as superseding TE either fully or at least substantially. After explaining these views, I'll present a third option that has gotten less attention - that we may view the two approaches as mostly complementary even if they are exclusionary in some aspects.

First, we can view the two approaches as competing. It seems that only Riedl and Gontier take this position. Gontier thinks that EE "declares all other philosophical disciplines bankrupt," 
and she explains this move as necessary because traditional epistemologies have all ultimately turned out to be unhelpful (2006, p. 1). In traditional philosophy, she writes, the first goal of an epistemology was to base science on some more foundational philosophy, as is illustrated by the rationalist and empiricist schools of thought. The idea was that there is a direct relation between the knower and either something that is known (this is rationalism) or else knowable (this is empiricism); she calls both views naïve realism, a position she finds untenable (p. 3). Gontier assumes a critical realist view and suggests that we follow Quine in attempting to base scientific thinking on scientific theories (p. 8). Gontier says that EE is a scientific discipline, as well as a philosophical a discipline intended for constructing a normative framework for epistemologies in general (pp. 1-2). On the other hand, Gontier thinks, unlike some proponents of EE, that a goal of EE is to develop a normative framework to be applied to cognition and decision-making. However, because Gontier characterizes EE as “a branch within” naturalized epistemology (p. 9), it doesn't seem that her version of EE can be a replacement of TE. You may wonder: doesn't Gontier's position mean that EE cannot even be a replacement for TE? We'll explore this issue in a moment.

We may sum up this position as claiming that in EE we give up hope for a foundation of all knowledge (and, probably, any hope for proving ontological realism). In short, EE competes with the TE stance that we should either try to justify certain fundamental claims or a certain way of obtaining knowledge, or, on the other hand, simply assert complete fallibilism or subjective idealism — all of which EE denies.

Some writers in EE, however, present their theory as superseding TE, replacing the "grand old paradigm" that emerged from the questions and solutions that concerned the early moderns (Churchland 1987, p. 546). Quine wrote that epistemology, or something like it (now that philosophers despair of real epistemology), ends up as "a chapter of psychology and hence 
of natural science" if we embrace his naturalism (1969, p. 82). Since TE did not get us anywhere near the goals it had, we should abandon it and carry on with science as the primary source of answers. Similarly, Churchland declares, "Since it is, after all, the nervous system that achieves these things [representation], the fundamental epistemological question can be reformulated thus: How does the brain work?" (1987, p. 546). Thus, this position aims to address mostly the same questions but to produce explanations that are incommensurable with traditional ones.

\section{A Third Option}

Although some proponents of naturalized epistemologies would like to do away with traditional epistemology, not all philosophers of a naturalistic bent think so. A third option has not gotten much detailed treatment even though Campbell takes the position. This view is that EE can be seen as either fully or mostly complementary to traditional epistemology.

Campbell said that, although EE is mostly about description of epistemological mechanisms and processes, it "must also be analytically consistent" and that, when forming an EE, we are interested only in those epistemologies that are "compatible with the description of man and of the world provided by contemporary science" (1974b, p. 413). Therefore, any other epistemology that does not deny the results of evolutionary biology, psychology, anthropology, etc. may be taken together with the results of EE.

Campbell believes that EE was developed because some philosophers saw traditional epistemology as excessively and unprofitably caught up with skeptical issues and not focusing enough on questions more immediate to our situation and answerable with scientific methods. The EE approach is to view knowledge as a phenomenon to be studied by the methods of biology. The focus, to repeat, turned to "handling expansions of knowledge, breakouts from the limits of prior wisdom, scientific discovery" (Campbell 1974b, p. 417).

Gontier's view that EE is a scientific discipline as well as a philosophical discipline 
intended for constructing a normative framework for epistemologies in general prompts the question doesn't this mean that EE cannot even be a replacement for TE? If the two fields and approaches are about different kinds of things but sharing the goal to provide normative judgments, why can't each do its own work without being concerned with what's being said in the other? Similarly, Quine acknowledges that relying on facts from science to justify science had always been seen as illegitimate. He contends, nonetheless, that there's nothing wrong with such a methodology if our goal is just to "understand the link between observation [Quine uses the word interchangeably with sense data] and science" (1969, pp. 74-75). Thus his radically new approach to explaining our knowledge does away with traditional epistemology only to the extent that his naturalized epistemology makes the traditional problems pointless.

Similarly, epistemology could follow Churchland's suggestion to set all focus on the question "How does the brain work?" But this question isn't clearly a philosophical question and seems better suited for the fields of neuroscience or (cognitive) psychology. If we're interested in the "grand old" philosophical questions (Churchland 1987, p. 546), we could keep pondering them while agreeing that scientific questions about the brain are also important for certain other aims. A skeptic could still ask whether there's any reason to think that we have any knowledge about the world in the first place.

That is also the point Jaegwon Kim (1988) makes about Quine's argument. Kim argues that, since Quine's naturalized epistemology doesn't share the same concerns as traditional normative epistemology, it's not clear how it can replace TE or be a better way of doing it (p. 391). Kim argues that Quine is right in agreeing with Hume that you can't through logical deduction validate science on the basis of sensory experience (p. 386); but Quine also suggests that we quit trying to validate science and instead try to study cognition only psychologically. Quine's proposed project is only descriptive, not normative or evaluative, and he's asking us to 
repudiate normativity (pp. 388-389). If Quine was proposing only a scientific discipline (studying how sensory stimuli affect cognitive processes), then his attempt to relate traditional epistemology to his naturalized epistemology is, in the words of Kim, "at best lame" (p. 390). Kaspar (1984) thinks of EE as a "biological branch of science" which nevertheless has implications for philosophical questions about, for example, the role of humanity in the universe and the non-existence of purpose in life (pp. 64-65). In other words, EE is philosophical only insofar as it indicates something about ethics or meaning, and its real task is "to examine the historical realization of the biological foundations of human cognition, and discover what influence those fundamental principles have on reason" (p. 64). Accordingly, EE does not and cannot answer all questions regarding knowledge or reason; it can contribute only to those aspects of "thinking and recognizing" whose evolutionary history it can reconstruct (p. 65). Kaspar thinks, therefore, that one can do all sorts of other philosophy while also accepting the consequences of EE. Indeed, it's part of the ratiomorphic apparatus to attribute meaning or purpose to various things in experience (pp. 62-63). Yet any claim about real purpose in the natural world is false if it conflicts with what we know about the naturalness of evolution.

Bradie and Harms (2017) believe that EE is meant to "provide a descriptive account of knowing mechanisms while leaving the prescriptive aspects of epistemology to more traditional approaches." At best, they write, EE could rule out normative approaches that are implausible or inconsistent with evolutionary science.

On the other hand, Campbell thinks of EE as partly normative, and Quine, in his later works, retreated from the view that a naturalized epistemology should replace TE and conceded that epistemology can be more than merely descriptive (Quine 1986, pp. 663-665; Quine 1990). Quine ends up writing that naturalized epistemology is, in general, about developing increasingly better heuristics for the "rational conjecture" of hypotheses in science (1990, p. 20). Given our 
aims for a useful and instructive science, epistemology can help establish which strategies are good to attain this aim. Quine doesn't see his position of making empirically testable predictions the "checkpoints" of science as itself normative; rather, having testable predictions is what defines the language game (in Wittgenstein's sense) of science. The relevant purpose of epistemology here is instead to offer such normative strictures as those of empiricism, such as the denial of clairvoyance; science itself does not contain commitment to physicalism — the view that everything in the world is fully due to physical (non-supernatural) causes (pp. 20-21). How could science establish that there's nothing non-physical? Nonetheless, thinks Quine, it would be "idle" to define science out of the unlikely possibility that non-physical things can be accepted, "to bulwark definition against implausible contingencies" (p. 21).

So can EE properly replace TE? The bottom line is that justification, and therefore knowledge, is essentially a normative concept, and "the concept of evidence is inseparable from that of justification" (Kim 1988, pp. 383, 389-390). A fully naturalized epistemology's version of "evidence" (sensory input) does not stand in an evidential relation to "theory" in that such evidence can't lend support for, or enhance the justification of, any particular theory, since “evidential relations hold in part because of the 'contents' of the items involved" (Kim 1988, pp. 390-391). Moreover, to even be able to engage in naturalized epistemology we'd need to have a theory for how to "find out what particular beliefs the given cognizers have formed," but this isn't possible without constant normative evaluations of cognitive output as coherent beliefs or theories (pp. 393-394). Therefore, an epistemology that takes the naturalized, in Quine's sense, view of evidence and theory must be constrained in its normative aims.

\section{Conclusion}

We have seen that EE is the product of a number of earlier philosophies that emphasized empirical experience as the basis of philosophical ideas; it is the culmination of attempts to 
naturalize epistemology as well as to explain cognition and knowledge from the standpoint of evolution. It maintains that biological aspects of evolution can be extrapolated to the analysis of knowledge and reasoning mechanisms, even scientific reasoning. And it thereby challenges every epistemology to account for the fact that we human knowers are natural beings.

Why should we care about this evolutionary way of doing epistemology? It seems that, if a philosopher is interested in the old, traditional questions - for example, how to distinguish mere belief from knowledge - then EE may not have much to contribute. On the other hand, EE asks the crucial question whether, as had been suggested by Quine and others, such questions are moot. Or, at least, perhaps we should forget about them, or see them as less important than the questions that we have a real chance of answering using the methods of science.

What other positions, then, would you need to commit to if you take the EE approach? One question that seems to have been unduly neglected is the appropriate theory of truth and the related question about realism. Some philosophers argue that EE does not dictate a particular theory of truth but goes well with, for example, some form of coherentism (Wuketits). Others have argued that EE only makes sense on a correspondence theory (Vollmer 2004). Is one theory of truth more compatible with EE? It's not clear, and this needs to be studied more extensively.

Additionally, the consensus is that some form of ontological realism must be assumed in any EE. Wuketits argues for a hypothetical realism, Popper for a critical realism (or critical rationalism). Campbell takes a "critical hypothetical realism" (1974, p. 447). Other thinkers in EE take other, similar, views. We will find EE acceptable only insofar as we find such a realism acceptable. Even though Campbell shows that you can't accept EE and remain a "naive realist," he thinks the limits of our senses only limit us and not the reality of the world (1974, p. 446). Some adherents of EE have argued directly for some form of realism. Vollmer (2004) mounts an impressive argument for the view that realism, as a premise of natural science, must 
be the most plausible view given the huge practical success science has had (though the success of a theory does not demonstrate its truth). Moreover, the antirealist cannot explain a theory's failure but can only describe the failure- "in what sense the theory has failed" (p. 207). On realism, there is a fact to the matter of how the world is, and a theory fails when it's wrong about what the world is like. And convergence is another phenomenon antirealists cannot explain: just as there is convergence in evolutionary biology (when similar traits originate independently in different species because of similar or identical external conditions), there are many cases of convergence in science: convergence of measurements, measuring methods, and theories ( $\mathrm{p}$. 209). This is what we should expect in a naturalistic and a realistic worldview.

Yet EE seems to be unable to establish realism as the correct view. In TE, this remained more of an open question. The problem that remains to be answered in EE is whether, perhaps, we need not succumb to the conclusion that "the notion of a world-in-itself becomes obsolete or at least redundant" (Wuketits 2006, p. 43; Churchland 1987). Contrast this to a view like Kant's, who tries to at least give a "Refutation of Idealism"; or Descartes, who tries to show there is an external world. If EE abandons pursuit for answers to traditional questions on traditional terms, does this imply that we need to re-define fundamental concepts such as truth and reality? This is in fact what some have suggested. ("What counts for any organism is that it copes with its own world properly" (Wuketits 2006).) This leads to a wholly new outlook on the realism-idealismantirealism problem, a matter that EE has not given a final verdict.

On another note, a tension I'm noticing within EE is that some thinkers present EE as extending by analogy from evolutionary biology to explain cognitive processes or increases in knowledge while others avoid talk of analogies but describe evolution as an abstract theory that is evident in both biology and scientific knowledge processes. Therefore, scientific progress is either analogous to (biological) natural selection, or it's an instance of a universal model of 
evolutionary change. It seems to me that it was more common in the earlier days of EE for thinkers to speak about how EE extends the biological theory of evolution by analogy (Plotkin 1987, pp. 302-303). On the other hand, Andersson stresses that EE theories shouldn't consider cognitive processes to be analogous to biological evolutionary processes: the two are variants of a more general process of interaction, memory, and synthesis (2008, p. 230). Andersson thinks that it helps to abstract away from particular selection theories of any discipline and identify the general form of selection, since this enable us to have fruitful discourse across disciplines. Extending another discipline's selection theory by analogy "threatens not only to mislead but to make discourse altogether impossible" (p. 230). We need a meta-theory that can incorporate "nested hierarchies of knowledge systems; systems whose dynamics are causally interlocked but that operate on different scales of time and space" (p. 233). That is precisely the kind of framework for which EE may prove as a useful guide.

Finally, the philosophy of mind that one ought to take in a consistent EE has not been fully fleshed out. Some philosophers subscribe to materialism, others to an emergentism. We also have Wuketits, one of the most important EE philosophers, who at first held a materialist or physicalist view but then moved over to an emergentism (Wuketits 1990). EE doesn't seem to imply a particular theory, except in denying dualism or any view that does not place the physical substrates of cognition as a central component of understanding the mind. 


\section{Works Cited}

Akeroyd, F. Michael. "Popper's evolutionary epistemology revamped.” Journal for General Philosophy of Science, vol. 35, no. 2, 2004, pp. 385-396.

Andersson, Claes. "Sophisticated selectionism as a general theory of knowledge." Biology \& Philosophy, vol. 23, no. 2, 2008, pp. 229-242.

Ariew, Roger and Eric Watkins, editors. Modern Philosophy: An Anthology of Primary Sources, 2nd ed. Hackett Publishing Company, 2009.

Bradie, Michael and William Harms. "Evolutionary Epistemology." The Stanford Encyclopedia of Philosophy, Spring 2017 Edition, edited by Edward N. Zalta.

Campbell, Donald T. “'Downward Causation’ in Hierarchically Organised Biological Systems.” Studies in the Philosophy of Biology: Reduction and Related Problems, edited by F.J. Ayala and T. Dobzhansky, 1974, pp. 179-186.

Campbell, Donald T. "Evolutionary Epistemology," The Philosophy of Karl Popper, edited by Paul Arthur Schilpp, 1974, pp. 413-463.

Campbell, Donald T. "Neurobiological Embodiments of Belief and the Gaps in the Fit of Phenomena to Noumena." Naturalistic Epistemology: A Symposium of Two Decades, Abner Shimony and Debra Nails (eds.). D. Reidel Publishing Company, pp. 165-192, 1987.

Churchland, Patricia Smith. "Epistemology in the age of neuroscience." The Journal of Philosophy, 1987. pp. 544-553.

Creath, Richard. "Logical Empiricism.” The Stanford Encyclopedia of Philosophy, Fall 2017 Edition, edited by Edward N. Zalta.

Darwin, Charles. The Origin of Species by Means of Natural Selection, 6th ed. London: John Murray, 1875. 
Gontier, Nathalie. "Introduction to evolutionary epistemology, language and culture." Evolutionary Epistemology, Language and Culture: A Non-Adaptationist, Systems Theoretical Approach, edited by Gontier, Nathalie, Jean Paul van Bendegem, and Diederik Aerts, Dordrecht, Springer, 2006, pp. 1-29.

Kant, Immanuel. Critique of Pure Reason, Unified Edition. Translated by Werner S. Pluhar, Hackett Publishing Company, 1996.

Kaspar, Robert. "A Short Introduction to the Biological Principles of Evolutionary Epistemology." Concepts and Approaches in Evolutionary Epistemology, edited by Franz M. Wuketits. D. Reidel Publishing Company, 1984.

Kim, Jaegwon. “What is 'Naturalized Epistemology'?.” Philosophical Perspectives, vol. 2, 1988, pp. $381-405$.

Kuhn, Thomas S. The Structure of Scientific Revolutions, 4th ed. University of Chicago Press, 2012.

Plotkin, H. C. "Evolutionary Epistemology as Science." Biology and Philosophy, vol. 2, no. 3, 1987, pp. 295-313.

Popper, Karl. Conjectures and Refutations. 3rd ed., Routledge \& Kegan Paul, 2002 [1963].

Quine, W. V. "Epistemology Naturalized." Ontological Relativity and Other Essays, Columbia University Press, 1969.

Quine, W. V. "Reply to Morton White." The Philosophy of W.V. Quine, edited by Lewis Edwin Hahn and Paul Arthur Schilpp, 1986.

Quine, W. V. Pursuit of Truth, Harvard University Press, 1990.

Riedl, Rupert. "Evolution and Evolutionary Knowledge: On the Correspondence Between Cognitive Order and Nature." In Concepts and Approaches in Evolutionary Epistemology, edited by Franz M. Wuketits. D. Reidel Publishing Company, 1984. 
Ruse, Michael. Taking Darwin Seriously: A Naturalistic Approach to Philosophy. 2nd ed., Prometheus Books, 1998.

Thagard, Paul. "Against evolutionary epistemology.” PSA: Proceedings of the Biennial Meeting of the Philosophy of Science Association, vol. 1, 1980, pp. 187-196.

Vollmer, Gerhard. "Mesocosm and Objective Knowledge.” Concepts and Approaches in Evolutionary Epistemology, edited by Franz M. Wuketits. D. Reidel Publishing Company, 1984.

Vollmer, Gerhard. "New arguments in evolutionary epistemology." Ludus Vitalis, vol. 12, no. 21, 2004, pp. 197-212.

Weber, Bruce H., and David J. Depew. "Natural selection and self-organization.” Biology and Philosophy, vol. 11, no. 1, 1996, pp. 33-65.

Wuketits, Franz M. "Evolutionary Epistemology - A Challenge to Science and Philosophy." Concepts and Approaches in Evolutionary Epistemology, edited by Franz M. Wuketits. D. Reidel Publishing Company, 1984.

Wuketits, Franz M. Evolutionary Epistemology and Its Implications for Humankind. Albany: SUNY Press, 1990.

Wuketits, Franz M. "Evolutionary epistemology: The non-adaptationist approach.” Evolutionary Epistemology, Language and Culture, edited by Nathalie Gontier, Jean Paul van Bendegem, and Diederik Aerts, Dordrecht: Springer, 2006, 33-46. 


\section{Annotated Bibliography}

\section{Akeroyd, F. Michael. "Popper's evolutionary epistemology revamped.” Journal for General} Philosophy of Science, vol. 35, no. 2, 2004, pp. 385-396.

This author argues that key points in Popper's approach were analogies between the way biological species develop and the way scientific theories develop (385-386). Popper believed that evolution in biology leads to "higher" forms, a process called orthogenesis, but modern biology does not include the view that organisms evolve in any particular direction (386). On the question of whether evolution is blind or random, Popper's view turns out to accord with recent developments in genetics (387-388). Organisms are modular to the extent that they can retain features of predecessors while evolving, and they can develop responses to the environment in ways that don't mirror a random walk; this is analogous to how Popper sees science (388). Internal mechanisms in organisms that constrain variation to bias it toward fruitful developments are like ("planned groping") orthogenesis in science (388-389). Developments in science tend to be less Lamarckian and more Darwinian $(391,395)$.

Andersson, Claes. "Sophisticated selectionism as a general theory of knowledge." Biology \& Philosophy, vol. 23, no. 2, 2008, pp. 229-242.

The natural selection component of evolutionary theory can be extended and applied to fields other than biology, for which Darwin did not intend his theory. By identifying and applying generalizable concepts of selection theory we can gain insights in disciplines beyond biology, and there have been attempts to do this for several decades (229-230). Yet selection theories have been the most helpful (even breakthrough) when they are grounded in empirical data, and progress has been made in the areas of clonal selection and neurophysiology but not really in the social sciences (230). (The author repeatedly says that explanations of cultural evolution by means of blind variation and selection alone are not sufficient $(230,232,241)$.) Philosophical theories should be informed by science, or at least by basic observation (230). It helps to abstract away from particular selection theories of any discipline and identify the general form of selection, since this enable us to have fruitful discourse across disciplines. Extending another discipline's selection theory by analogy "threatens not only to mislead but to make discourse altogether impossible" (230). Selection isn't a perfect theory for much of human knowledge progress because humans gain knowledge in a way that appears as if we can to some extent 
predict (unlike blind natural selection of organisms) what belief or theory is more likely to be more accurate (231). The basic assumption that the scientific way to explain this appearance of prescience must not invoke anything like miracles and only constrains theories but does not itself explain what theories working within this constraint may explain (231-232). A theory may allow "proximate prescience" at some level of organization even if this concept is forbidden at other levels (232). We need a general theory or a meta-theory that can incorporate "nested hierarchies of knowledge systems; systems whose dynamics are causally interlocked but that operate on different scales of time and space" (233). The author's proposed theory uses the three "fundamental functions" of interaction, memory, and synthesis (234).

\section{Bradie, Michael and William Harms. "Evolutionary Epistemology." The Stanford Encyclopedia} of Philosophy, Spring 2017 Edition, edited by Edward N. Zalta.

There have been, broadly, two projects of study within evolutionary epistemology: the first is about the evolution of epistemological mechanisms, and the second is about the evolutionary epistemology of theories. Both are based on analogies, models, and metaphors drawn from the biological theory of evolution, but the two programs are distinct in that neither implies the other and neither would invalidate the other if it were to fall. The author describes "traditional" epistemology as the history of attempts since Plato to (a) distinguish knowledge from true belief and (b) reconstruct all of human knowledge to show how it coherently fits together; but since the late 19th century an alternative approach has been proposed with the starting assumption being that, since humans are the product of evolution, some of the problem of human knowledge is to be explained scientifically. Thus there isn't a distinction made between science and philosophy, and philosophy is not supposed to establish the validity of science. Whereas the traditional approach assumes that the basic epistemological questions may not be based on any particular knowledge, the point being to avoid question begging, this new approach begins with the fact that we're able to have some knowledge as natural beings and that our nature in this respect may be studied naturalistically. The view called evolutionary epistemology is just a development of this approach with evolutionary considerations, and insights in this area help scientists understand certain aspects of biological evolution. Though in evolutionary biology there is a recognized difference between development during an organism's lifetime, as characterized by ontogenetic models, and a species' evolution, as characterized by phylogenetic models, in EE there is no distinction made along these boundaries, and it is generally not emphasized that biological 
processes of knowledge gain operate significantly differently from selectionist processes across time in cultures. Traditional epistemologies are normative, but EE can only describe knowledge processes without prescribing or evaluating the merits of different ways of forming beliefs. Some thinkers have proposed EE as competing with traditional normative epistemology, others have argued that EE should supersede traditional views which, they say, have not brought much philosophical progress, and still others view EE as complementary to traditional views.

Campbell, Donald T. “'Downward Causation” in Hierarchically Organised Biological Systems.” Studies in the Philosophy of Biology: Reduction and Related Problems, edited by F.J. Ayala and T. Dobzhansky, 1974, pp. 179-186.

Natural selection works at the phenotypic level, not at the genotypic (181). There is in nature the causation of particular DNA sequences (across generations) because of the functions organisms have in their environment and not just at the DNA or protein level (180-181). Organism-level selection determines the distribution of proteins "and hence the DNA templates guiding their production" (181). Campbell gives the example of worker termites and the distributions of jaw forms across groups of such termites; there is division of labor in that some termites are warriors in the group with their particular jaws (but can't feed themselves), others procure food, and others build living quarters (181). Only higher-level (in the ecological niche) selective pressures —or laws of selection - can produce social phenomena like this naturally. Campbell concludes from the existence of such social structures in nature that "for biological systems produced by natural selection, where there is a node of selection at a higher level, the higher level laws are necessary for a complete specification of phenomena both at the higher level and also for lower levels" (182). What appears to be designed at some level is explicable naturalistically at another level. Yet he states this doesn't mean the autonomy of higher levels, as if natural processes at the molecular level don't matter (182). One implication is that we each have beliefs in part caused by higher-level social structures that we can't always explain or show to be right or wrong.

Campbell, Donald T. "Evolutionary Epistemology," The Philosophy of Karl Popper, edited by Paul Arthur Schilpp, 1974, pp. 413-463.

Campbell begins by defining what must at minimum be true of an epistemological theory if it should be considered an evolutionary epistemology: the theory should be informed by and compatible with what we know about how humans have evolved biologically and socially by 
natural processes (413). Campbell interprets evolution to be "a knowledge process"-meaning that an organism's evolution is a kind of learning; and the natural selection part of evolutionary theory can be generalized to understand other epistemic activities like thought and science (413). Campbell provides a descriptive, not a normative, EE theory (413). A "direct realism" is not compatible with this evolutionary model if the realism holds that we have veridical visual perception, since we must accept that our sensory organs and the phenomenon of language have evolved for purely pragmatic reasons and are not perfect (414). Our perceiving faculties do not give us ground for certainty about anything like scientific laws having analytic or absolute truthas shown by Hume (414). These faculties have evolved to help us survive, and necessarily we can only have a partial grasp of the world that's out there. Popper developed a core part of evolutionary epistemology by recognizing that the development of theories in science is similar to the development of organisms by natural selection (415). Popper was not trying simply to give another answer to the questions Hume dealt with - he changed focus and re-centered the epistemological problem: "The central requirement becomes an epistemology capable of handling expansions of knowledge, breakouts from the limits of prior wisdom, scientific discovery" (417). The study of scientific knowledge replaces Hume's problem of "reasonable belief" with the questions about how to accept to reject scientific theories. So Hume and Popper weren't really trying to answer the same questions. The evolutionary approach to epistemology gives up the traditional effort to hold back all knowledge until we establish that knowledge is possible, nor does the approach suspend sense data until there are indubitable grounds for its validity (418). We have no proven modes of knowing without basic presuppositions, and we accept that we can't refute solipsism — but those aren't the interesting problems. The "problem of knowledge" is in "truth claims descriptive of a more than now-phenomenal world" (418). So what we spend our time on in philosophy is explaining whether and to what extent, for example, we can allow unobservable entities or laws of nature. A process fundamental to all increases in knowledge is "blind-variation-and-selective-retention"- just as that's fundamental to "all increases in fit of system to environment" (421).

Churchland, Patricia Smith. "Epistemology in the age of neuroscience." The Journal of Philosophy, 1987. pp. 544-553.

Philosophers have been abandoning the "grand old paradigm" that emerged from the questions and solutions that first concerned Descartes, Locke, and Hume and then even the Logical 
Empiricists (546). Some of the concepts that arose out of the traditional (early modern) controversies have been getting less and less serious attention, and now more philosophers are questioning whether it's not "bizarre" to think that "a theory of meaning that has nothing whatever to do with human psychology or neurophysiology can explain the meaningfulness of language and how representational structures relate to the world" (545). Moreover, there are now "remarkable new developments in cognitive neurobiology which encourage us to think that a new and encompassing paradigm is emerging" (546). Churchland suggests that "Since it is, after all, the nervous system that achieves [representation of reality], the fundamental epistemological question can be reformulated thus: How does the brain work?" (546). This question calls for descriptions, yet Churchland does not want to eliminate normativity out of epistemology. We begin with adequate definitions of reasoning (for completing computational or representational tasks), and then we can identify what it means to reason well (546). Our brain and nervous system, as those of other organisms, evolved to enable us to cope with the ecological niche we find ourselves in, not necessarily to enable us to accumulate facts as propositional statements (548). (Also the epistemological theories we develop concerning information processing should be thoroughly informed by experiment (552).)

Gontier, Nathalie. "Introduction to evolutionary epistemology, language and culture." Evolutionary Epistemology, Language and Culture: A Non-Adaptationist, Systems Theoretical Approach, edited by Gontier, Nathalie, Jean Paul van Bendegem, and Diederik Aerts, Dordrecht, Springer, 2006, pp. 1-29.

The author begins with the claim that EE "declares all other philosophical disciplines bankrupt," and she explains this move as necessary because traditional epistemologies have ultimately turned out to be unhelpful (1). In traditional or classical philosophy, the first goal of an epistemology was to base science on some more foundational first philosophy, as is illustrated by the rationalist and empiricist schools of thought. The idea was that there is a direct relation between the knower and either something that is known (this is rationalism) or else knowable (this is empiricism); both views may be called naïve realism (3). Kant introduced an important turn in the philosophical tradition by suggesting, not only that our knowledge only comes from the external world, but also that the way the world appears to us in our thinking is shaped by internal structures of our mind. The a priori categories which necessarily dictate the kinds of ideas we can have about the external 
world, and our mind does not have direct access to signals from our sensory organs (4). EE is "a branch within" naturalized epistemology (9). The author says that EE is a scientific discipline as well as a philosophical a discipline intended for constructing a normative framework for epistemologies in general (1-2). EE makes normative judgments about how we should explain cognition and behavior evolutionarily. Natural selection and evolution are not synonymous in that natural selection is but one explanation of the phenomenon of evolution. Neo-Darwinism, or simply the synthesis of natural selection with Mendelian genetics, is just one theory intended for explaining the phenomenon of evolution, but it's not the only plausible one. Each organism is a system of knowledge that represents and contains information about its external world - whether or not the organism uses language or has a brain or sensory organs (10), so by studying an organism we can learn about the conditions within which it evolved. In this "traditional EE," evolution includes undirected hypotheses ("in the Popperian sense") about organisms and adaptations to the environment, which are either confirmed by an organism's relatively better survival or falsified when the novelty turns out to be maladaptive. Gontier introduces a "New EE" that takes the idea that an organism participates in the evolutionary learning process even further, a trend in EE since the 1980s that discards the distinction between ontogenesis and phylogenesis; natural selection may operate at other levels, not just with the phenotype, or with other units of selection (11-12). The external world for any organism is always changing. Adaptation is not necessarily the primary mechanism of evolution. Though adaptation to the environment is always present, organisms themselves also shape their evolution. Each organism is "able to change its environment to enhance its survival" and to self-maintain to some degree (15). Therefore, a universal selection-based theory is unlikely to be adequate for forms of evolution other than as seen in animals as traditionally studied by zoologists, and even for this latter kind of organism the active ingredient of the organism is important.

Kaspar, Robert. “A Short Introduction to the Biological Principles of Evolutionary Epistemology." Concepts and Approaches in Evolutionary Epistemology, edited by Franz M. Wuketits. D. Reidel Publishing Company, 1984.

Although classical thermodynamics may seem to prohibit the self-ordering of natural systems, in fact evolution is about open systems that need to be taken with the context of their surroundings (51). At every level of complexity in organic structures, selection is active in "testing" sub- 
components within their direct surroundings, or, more precisely, within each structure's "next subordinated system" (53). Therefore, to understand large complex systems, we need to see each nested hierarchy as being selected for within its own immediate context—not as selected to contribute to the organism viewed at the broadest level. There are evolutionary feedback cycles at every level of hierarchically organized systems (51-53). Each structure in a biological system is adapted just to one part of the environment, so "organisms do not represent the world "in itself", but only in the pragmatic sense, obtain "knowledge" about conditions which are relevant in a concrete situation" (54). Cognition-gaining is driven by the same principle of self-organization that drives the development of nervous systems (55).

Kim, Jaegwon. "What is 'Naturalized Epistemology'?.” Philosophical Perspectives, vol. 2, 1988, pp. 381-405.

Western epistemology has been concerned with broadly two tasks since Descartes: to identify the criteria of justified belief and to determine what we really know by those criteria. Modern epistemology has been dominated by study of the concept of justification (381). The criteria of justified belief must not include normative or evaluative terms, but epistemology is essentially a normative discipline in evaluating how we must accept or reject beliefs (382-383). Quine denounced not only (Cartesian) foundationalist epistemology but also traditional (modern) normative epistemology (385). Quine is right in agreeing with Hume that you can't through logical deduction validate science on the basis of sensory experience (386); but he also suggests that we quit trying to validate science and instead try to study cognitive processes psychologically (387). Quine's proposed project is only descriptive, not normative or evaluative, and he's asking us to repudiate normativity (388-389). If Quine was proposing only a scientific discipline (studying how sensory stimuli affect cognitive processes), then his attempt to relate traditional epistemology to his naturalized epistemology is "at best lame" (390). Justification and therefore knowledge are essentially normative concepts, and "the concept of evidence is inseparable from that of justification" $(383,389-390)$. The relation between naturalized epistemology's versions of "evidence" (sensory input) and "theory" do not stand in an evidential relation in that this evidence can't lend support for, or enhance the justification of, any particular theory, since "evidential relations hold in part because of the 'contents' of the items involved" (390-391). Thus, since naturalized epistemology doesn't share the same concerns as traditional normative epistemology, it's not clear how naturalized epistemology can replace traditional epistemology or be a better 
way of doing it (391). Moreover, to even be able to engage in naturalized epistemology we'd need to have a theory for how to "find out what particular beliefs the given cognizers have formed" (394); but this isn't possible without constant normative evaluations of cognitive output as coherent beliefs or theories (393-394).

\section{Kuhn, Thomas S. The Structure of Scientific Revolutions, 4th ed. University of Chicago Press,} 2012.

According to Kuhn, scientists always (or sometimes after an initial pre-paradigm state of general confusion in the discipline; 15,48 ) work within some paradigm. A paradigm is a scientific community's set of commitments to fundamental questions about what the world is like, what we can know about it, and how we should go about answering the community's questions (4). These assumptions are based on background knowledge and concepts of the scientists in the discipline from the education and training they receive and sometimes because of the definitions used for various concepts. In evaluating the work of a scientist, the whole population of relevant scientists will be guided by the assumptions that the scientists have in common. The researchers in any field become qualified researchers by being exposed to exemplary instances of proper scientific research in their field, which help them learn what is expected of them in the discipline (10). Kuhn argues that most scientists throughout most of their career engage only in (relatively insignificant) science that does not challenge important assumptions that most scientists have accepted; most of their work is not groundbreaking but merely solves "puzzles" that have arisen through the work of scientists in the field. This gives science its "peculiar efficiency" in solving problems (239). Sooner or later, any discipline begins to encounter anomalies to the working theories. Any anomaly to the received paradigm is addressed by researchers so that the paradigm can accommodate the anomaly. When something surprising or inexplicable is observed, scientists don't easily conclude that their entire scientific paradigm is mistaken but see a challenge to perfect their understanding of the theories in the paradigm or adjust some assumptions they require for their theories or models. Eventually, a period of crisis comes upon each discipline, and then comes a scientific revolution, which is a wholesale abandonment of one paradigm and the adoption of another. The existing data either becomes worthless or is then understood in a new way. It becomes impossible to compare theories in two different paradigms given "the data"-for the data will be different in the two paradigms; this is what it means for theories in different paradigms to be "incommensurable" $(147-149,156)$. This entire process repeats cyclically. 
Plotkin, H. C. "Evolutionary Epistemology as Science.” Biology and Philosophy, vol. 2, no. 3, 1987, pp. 295-313.

The literature in evolutionary epistemology grew tremendously between 1974 and 1987, at the rate of science, but by far most EE is not science; it isn't part of the biology science that aims to explain how and why humans and animals come to know about their world (295-296). The difference between philosophy and science has to do with "the accessibility of the product of analysis, of a theory, to empirical test," where accessibility is "judged in terms of the intention of disciplining a theory by empirical testing" (296). To continue to flourish, EE needs a scientific base of its own, since at the core EE holds that knowledge is an issue to be addressed through science, particularly through evolutionary biology (297). EE studies also how humans have been able to cause their own evolution to some extent by an "exploitive system": some species (a small number) have evolved the capacity to make decisions that "alter the natural selection pressures operating upon these animals"-for example by choosing the environments in which to live (298-299). The claim that cognitive processes are evolutionary processes is highly contentious, mostly a scientific question, and "will not be solved by analysis alone" (302). To continue to be seen as at least in part scientific, evolutionary epistemology must contribute to developing a conceptual scheme or model that integrates genetics, epigenetics, and cognition to account for the "knowing" about its environment that a set of adaptations can exhibit (309). The scheme will likely be a nested hierarchy involving the levels genetic, genetic-developmental, and geneticdevelopmental-cognitive; "no cognitive process can ever operate as a tabula rasa mechanism" but relies on the more fundamental processes in genetics and epigenetics (309). Cognitive processes have evolved because genes acting alone are limited in the way they can equip phenotypes to deal with the environment: "If these cognitive processes did not exist, then the explanation of the behavior of these phenotypes could be reduced to differences in the genetic endowment of individual phenotypes" (301). Cognitive processes allow semi-autonomous decisions for individuals within their lifetime. Exploitive system: there must be involved a kind of organism-influenced evolution through the organism's decisions.

Popper, Karl. Conjectures and Refutations. 3rd ed., Routledge \& Kegan Paul, 2002 [1963]. The book develops a theory of (the growth of) knowledge based on the simple overarching premise that we can learn from our mistakes. Rational arguments are supposed to criticize our 
mistakes, and observations in experience are relied on to test our beliefs. We are fallible always, but this does not imply skepticism. Our knowledge can grow and progress. All of our knowledge (including scientific knowledge) progresses by way of unjustifiable guesses or conjectures, which are controlled by criticism and attempted refutations. That is, any tentative solution to a problem is put to severe testing. We gain some knowledge when we refute a proposed conjecture, but we can never fully prove a hypothesis or even demonstrate that it's probably true. A hypothesis or a solution to a problem can be considered scientific to the extent that it is testable. Popper criticizes the doctrine that truth is manifest - that, when put naked before us, the truth is recognizable as true (8-9). Such a doctrine was central to the epistemologies of both Descartes and Bacon. It's a mistake to think that one can sometimes see that something is the truth, and such a view breeds fanaticism and authoritarianism when it is said that you need to be in a special cognitive state to perceive the truth (10-11). Popper asks, "But what, then, are the sources of our knowledge?" His answer: "there are all kinds of sources of our knowledge; but none has authority" (32). Popper finds it fruitful to ask, instead of what source of knowledge is best, the question of how we can "detect and eliminate error"- since pure and certain sources of knowledge do not exist (33-34). Together with the proposition that we can hope to detect and eliminate error by criticizing theories and guesses Popper calls this position on knowledge critical rationalism (34).

Quine, W. V. "Epistemology Naturalized.” Ontological Relativity and Other Essays, Columbia University Press, 1969.

Progress has been made in understanding the foundations of science by the efforts to ground mathematics in logic, or in logic and set theory; and this success is exemplary (69). But, though this reduction can and does help us better understand how some concepts interrelate, it does not go all the way to "reveal the ground of mathematical knowledge, it does not show how mathematical certainty is possible"- - which is what epistemologists are ultimately interested in (70). Hume identified the bodies of us knowers with sense impressions, but this put him in a difficult position for justifying our scientific knowledge (71). Quine does not see that we've made any progress since Hume in justifying our "knowledge of truths of nature in sensory terms" (71). Carnap got close to enabling us to translate sentences about the world in terms of sense data, logic, and set theory, though it was acknowledged that this wouldn't establish certainty or allow hypotheses to be (logically) proved in science (74). It would've not only been good to have a rational account of "physicalistic discourse," but it'd obviously be reasonably grounded because 
"The stimulation of his sensory receptors is all the evidence anybody has had to go on, ultimately, in arriving at his picture of the world" (75). Quine suggests, "Why not settle for psychology?" (75). Previously, attempts to validate science by relying on science were seen as illegitimate, but there's nothing wrong if our goal is just to "understand the link between observation [Quine uses the word interchangeably with sense data] and science" (74-75). We get a "verification theory of meaning" (80) if we suppose that the "meaning of a statement consists in the difference its truth would make to possible experience" (78). A single sentence by itself can have no meaning at all because you won't be able to identify its implications for empirical experience. But a theory of several connected sentences taken together will have meaning because the theory will make verifiable predictions or have implications for the observable world (79). Epistemology, or something like it (now that philosophers despair of real epistemology), has ended up as "a chapter of psychology and hence of natural science" (82).

Riedl, Rupert. "Evolution and Evolutionary Knowledge: On the Correspondence Between Cognitive Order and Nature." In Concepts and Approaches in Evolutionary Epistemology, edited by Franz M. Wuketits. D. Reidel Publishing Company, 1984. The author develops an early systems-theoretical approach to biology and epistemology. He believes that Kuhn "convincingly portrayed the process" of how paradigms, theories, and worldviews change, but he thought that what still needed to be explained is how some insights spread very quickly even though others are overlooked for a while until they resurface (35-36). In his scientific career, Riedl was interested in explaining the harmony between (morphological) structures in organisms and their external conditions (35-36); after extensive research, he concluded that "to examine history for regularities, a consistent theory is needed" but that such a theory did not yet exist (36). He believed that plain old Darwinism could not sufficiently explain the fit between organisms and their environment. Nature exhibits nested hierarchies of order, a fact that has been overlooked among researchers working solely in traditional Darwinian natural selection theory (38). There is a kind of "correspondence between cognitive and natural order" that is not easily explained as due to chance- "One had to be the cause of the other" (39); and it concerned Riedl early in his research days that it was generally accepted that "Natural order was explicable but not cognitive order" (39). Riedl became drawn to the possibility that cognitive order could be "a selection product of natural order" (39). Hierarchy in nature is not a mere 
thought projection by us (40). Based on his scientific evidence, Riedl establishes that humans possess a certain "system of hypotheses" innately—-that is, genetically stabilized patterns of cognition (40-44), or "hereditary decision aids of living systems" (46). This system of hypotheses evolved in its particular way because of corresponding realities in the world. This theory makes sense only if there is some kind of reality existing independently of living systems. Yet commitment to this premise does not commit one to the position that external conditions evolve independently of the contained living systems. The set of Kantian a priori categories are "the most fundamental preconditions of our ... conscious reason. Since they are its ultimate preconditions, they are not to be justified by reason alone" (46) - and we can study them by the methods of natural science.

Thagard, Paul. "Against evolutionary epistemology.” PSA: Proceedings of the Biennial Meeting of the Philosophy of Science Association, vol. 1, 1980, pp. 187-196.

This author considers the EE program that deals with the growth of scientific knowledge (not the evolution of epistemological mechanisms), taking such epistemologies to rely on analogies between biological and epistemological theories (187). He argues that "similarities between biological and scientific development are superficial" and that non-Darwinian approaches to "historical epistemology" are superior (187). An essential part of naturalistic evolution is blind variation, which means that variations arise without regard to the specific needs of the individual or species and are not corrections of previous variations (188). Yet scientific developments result from concern with specific recognized problems and are intended by scientists to solve the problems (188). Science proceeds by abductive inference as hypotheses are proposed as explanations of puzzling phenomena (188-189). Moreover, it can't be that all or most scientific hypotheses are invented randomly or blindly, for that wouldn't account for the obvious rate of progress in science (189). Also, the rate at which novel scientific theories and concepts are produced in a discipline depends on the degree to which a scientific paradigm of the relevant scientists is in crisis (when the paradigm is close to being replaced); yet the rate of evolutionary innovation does not thus depend on environmental stresses (190). And on the selection side, there is a difference between biological evolution and theory evolution in science: it is intentional agents who select theories according to global scientific goals of "finding solutions to problems, explaining facts, achieving simplicity, making accurate predictions, and so on"-all of which depends in part on (subjective) motivations of scientists (190-191). In contrast, natural selection 
selects in a way that's pragmatic, without having underlying motivations, for particular local environments, and there's no way an organism can be inherently "fit" (190-191).

\section{Vollmer, Gerhard. "Mesocosm and Objective Knowledge." Concepts and Approaches in}

\section{Evolutionary Epistemology, edited by Franz M. Wuketits. D. Reidel Publishing} Company, 1984.

EE should be judged "Like any other theory in science"- by its explanatory power, testability, etc. (69). Yet EE is not purely a scientific discipline, for it "tries to solve a philosophical problem, to answer an epistemological question" (75). By EE the philosophical question is answered "with the help of a scientific theory" (76). The question is about explaining why there is far-reaching "agreement between objective structures (of the real world outside) and subjective structures (of our knowledge about this world)" (75). Thus Vollmer assumes that it's an empirical fact that there is this "agreement" between the outside world and our knowledge of it, and EE is an attempt to explain this fact. The answer given by EE is that it's not a coincidence, as some philosophers had supposed, or due to pre-established harmony, as Leibniz thought. The answer is, of course, that our cognitive mechanisms are results of biological evolution and therefore cohere with "objective structures of the world" because they've adapted- "they are partially isomorphic to this world because otherwise we could not have survived" (75). Biological organs do not represent or portray external conditions as some thinkers had said (e.g., Lorenz); the organ may not even mirror an aspect of the world (71-72). That's because the organ is a different thing from the conditions within which it evolves: "The sun and the eye have nothing in common" (71). Yet organs that are retained over evolutionary time at least hint at what must be true about the environment (72). For example, by studying a particular tool we can infer what jobs it's suited for (e.g., a torch couldn't be used for unscrewing a bolt). It is only in this limited sense that we can say that an organism represents or mirrors its environment. And the fact that our sense organs are terrifically useful for our interactions with the environment does not mean that we get a true picture of reality by our senses (72). Kant rightly detected that the knowing subject has an important role in the formation of knowledge, yet he exaggerated it (71). The simplistic empiricist claim that cognition mirrors the outside world is incorrect. The knowing subject's own contribution to knowledge of the world is important.

Vollmer, Gerhard. "New arguments in evolutionary epistemology." Ludus Vitalis, vol. 12, no. 
21, 2004, pp. 197-212.

Evolutionary epistemology is constitutively based on the theory of organic evolution $(199,208)$.

Vollmer discusses "the biological evolution of cognitive faculties"- not the development of science using evolutionary concepts, which he calls evolutionary philosophy of science (199). When the brain constructs a picture of the world from the signals that flow from our sense organs, this picture is not fully dictated by external stimuli or by the sense organs themselves. Coherent cognition is possible because of the structures and mechanisms that have evolved for the human brain, and we naturally experience these in-built features as innate or even necessary. What may seem to us to be innate human nature is explainable by the framework of EE, a naturalistic position (197-198). Thinking is all done by the brain, which as an organ evolved organically to enable us to get by in what to us is a world of medium dimensions - the "mesocosm" (198). Evolution does not mean that the best possible features evolve but rather only that the most fitting adaptations will thrive best and be passed on to progeny, and the human brain and cognitive faculties for that reason evolved just to aid our survival in a subset of reality. Within this mesocosm, our natural intuitions, spontaneous judgments, and physical perceptions are generally reliable, but beyond the mesocosm, such as when doing scientific work with the very small, the very large, or the very complicated, human intuition fails regularly (198). EE does not include the idea that all epistemological problems can or should be solved by reference to evolution, but it does rest all of epistemology on organic evolution; the main idea is that "the evolutionary origin of our cognitive faculties plays an important role for epistemology, both explanatory and critical" (199). EE is distinguished as naturalistic by two traits: "by its universal claim [that "all over the world there are no secrets"] and by the limitation of tools being admitted for the description and explanation of the world" (199). Evolutionary epistemology defends a hypothetical realism which is characterized by realism at three levels: (1) ontological realism, which says that "there is a real world independent (for its existence) of our consciousness, lawfully structured, and quasicontinuous"; (2) epistemological realism, which says that "this world is partially knowable and understandable by perception, thinking, and an intersubjective science"; (3) fallibilism, which says that "our knowledge about this world is hypothetical and always preliminary" (200). We can get a better grasp of which human characteristics are genetically innate by comparing languages of different human groups (203-204). Realism is a fundamental premise of natural science; the huge successes of science testify to the realities presupposed by science. Advances and 
accomplished goals in science support realism, but we could always have several empirically equivalent theories that contradict each other in their basic premises, which indicates that the success of a theory does not demonstrate its truth (206). The existence of failed theories is a better argument for realism than the existence of successful theories (207). The antirealist cannot explain a theory's failure; the antirealist can only describe the failure - describe "in what sense the theory has failed" (207). The realist, however, explains a failed theory as being wrong about what the world is like. On realism, there is a fact to the matter of how the world is, and a theory fails when it's off the mark (207). Antirealists cannot explain the phenomenon of convergence, but realists explain it as possible (maybe even bound to happen) because there are real structures in the world which different people may observe independently (209).

Weber, Bruce H., and David J. Depew. "Natural selection and self-organization." Biology and Philosophy, vol. 11, no. 1, 1996, pp. 33-65.

From the earliest days of work in evolutionary theory, biologists have been assisted by models in physics (especially dynamics) for clarifying and quantifying concepts. There has been "a vital and vitalizing connection between Darwinism and dynamics" (34), and even though Darwinian research has always had some conception of natural selection at its core, the precise formulation of natural selection has been adjusted several times (33). The authors report that they're noticing a new shift in natural selection theories that are now taking account of recent growth in the field of nonlinear dynamics, which examines and explains phenomena of self-organization in complex systems (34). This should not be seen as a threat to the more traditional Darwinian models, for there may be fruitful results from evolutionary explanations that take into account chance and self-organization along with law-like conceptions of natural selection. Self-organization as conceived of by the authors is evident in genetic development, where it is not just chance and natural selection in operation (38). The natural selection that occurs at this level obviously is not about organisms being the unit of selection; this calls for a more general formulation of natural selection that can apply to organisms (in the study of phylogenesis) as well as to genes (in the study of both phylogenesis and ontogenesis) (39). The early conceptions of Darwinian evolution, even through the Modern Synthesis, did not anticipate the work that would be done with the very small (genes) and the very large (phyla), so plain Darwinian selectionism, though valid for a certain range of phenomena, is unable to explain evolution outside of this range (40-41). The authors believe that "Natural selection and self-organization are two aspects of a single 
evolutionary process" (45); and they stress that their explanation of evolution in terms of a complex interplay between natural selection, chance, and self-organization-rather than threatening the status of Darwinian natural selection as crucial to evolution - explains in a fully naturalistic way much phenomena that had hitherto attracted teleological concepts (57).

Wuketits, Franz M. "Evolutionary Epistemology - A Challenge to Science and Philosophy." Concepts and Approaches in Evolutionary Epistemology, edited by Franz M. Wuketits. D. Reidel Publishing Company, 1984.

Darwin developed some important first cornerstones of what became the field of evolutionary psychology, and his work was "founded on a mass of empirical evidence and did not lack scientific rigour" (1-2). Kant did not explain where a priori structures (categories of thought) come from. We can view EE as the "attempt to explain a priori structures of our knowledge via evolution and to 'dynamize' these structures" (4). In this way there is a kind of phylogenetic relativity of the Kantian categories. The first postulate of evolutionary epistemology is that learning and cognition during an individual's (or an animal's) lifetime is possible because "all organisms are equipped with a system of innate dispositions," which means that no organism starts off as a clean slate (5). No psychological or mental states are explicable "without reference to the organic level"- activity by a mind is due to specific arrangements of neurons (8); thus the mental life of humans can be understood only by studying the neurological basis of cognition (8). He stresses that ontological reductionism does not follow, and he says he adopts the emergentist view that "patterns of interaction on the organic level led to the emergence of" psychological and mental phenomena through evolution (8). Wuketits aims to escape from "metaphysical obscurantism"- traditional philosophical ruts in which thinkers have gotten hopelessly stuck; his suggestion: embrace some critical approach that saves the objectivity of science without committing us too naive views of realism (15). For example, he calls classical dualism a kind of obscurantism, a sad condition that is unsurprising given its not being based in science (8).

Wuketits, Franz M. Evolutionary Epistemology and Its Implications for Humankind. Albany: SUNY Press, 1990.

There have been two programs of EE: First, there is work intended to account for cognition in humans and animals by applying our understanding of biological evolution to the brain, central nervous system, and sensory organs. The second program deals with constructing a metatheory of 
rational knowledge and explaining culture and especially scientific progress in terms of evolution, or with universal evolution-like theories (5). Both programs accept that "evolution is to be taken as a basis for cognition processes of all kinds" (152), and evolution is a cognition and learning process (8). EE is about developing a non-reductionist framework taking as its most basic principles that humans evolved and that human cognitive and social capacities are at least in part due to evolution. A systems-theory approach is superior to a traditional adaptationist approach because it accounts for the fact that organisms partake in a feedback loop that influences their evolution. Organisms are not simply molded by their environment - they don't merely adapt. Cognitive structures produce a coherent scheme of external reality for organisms which shape their external conditions and constrain their evolution (153). Wuketits thus takes an organismcentric stance in thinking about evolution in contrast to the traditional adaptationist approach. That organisms constrain their environment is true at both levels of evolution studied in EE: the biological evolution of cognitive structures and mechanisms and cultural evolution in which humans play an active role with their teleological intentions (153). Kant could not explain where the categories and forms of intuition come from; the answer of EE is that they are results of evolution: a priori knowledge in humans is indeed "independent of individual experiences," but it came from "evolutionary learning processes of the particular species and thus a posteriori knowledge from the point of view of evolution" (82). EE presupposes "the existence of some kind of reality independent of any organism's perception. [EE] rests on what has been widely discussed under the term common sense realism" (189-190). Wuketits subscribes to hypothetical realism, which is that animals take the reality of the world as a basic operating hypothesis. To cope with the external world an organism needs to have a merely coherent view of reality, not necessarily a view of reality that corresponds to what is actually out there (193). Studying biological evolution can tell us a few basic things about how science develops, at least the question of to what extent intellectual activities are constrained by evolution (152).

Wuketits, Franz M. "Evolutionary epistemology: The non-adaptationist approach.” Evolutionary Epistemology, Language and Culture, edited by Nathalie Gontier, Jean Paul van Bendegem, and Diederik Aerts, Dordrecht: Springer, 2006, 33-46.

Wuketits differentiates his form of EE by pointing out that earlier EE frameworks, unlike his own, were based on or strongly informed by "the adaptationist paradigm," the view that 
organisms passively evolve to fit in with and mirror their external environment (33). This means, on the adaptationist approach, that all anatomical and behavioral characteristics of an organism can be explained as adaptations, and that an organism's perceiving apparatus gives it a true but simplified representation of some parts of the outer world (34-36). This view has a long history and can is seen, for example, in works by Konrad Lorenz, but it is now regarded by many modern evolution scholars as insufficient. But a more sophisticated and recent view of the last few decades takes an organismic perspective (or organism-centered), accounting for the way organisms take an active role in co-evolving with their environments. Wuketits presents his nonadaptationist version of EE as better informed scientifically, and he believes that it also applies to the program in EE that deals with the specific type of cognition in scientific knowledge $(34,37)$. Living systems are hierarchically organized and "open" at the various levels of biological order in the sense that internal systems interact with the other levels and constrain the form and extent of the organism's adaptability (38). There is constant feedback and causation directed both up and down the hierarchy (38; c.f. Campbell 1974b). Each organism will be able to survive long enough to reproduce to the extent that it's able to generate a life-supporting view of external reality. It need not believe anything about what the world may be like in itself; organisms, however, exhibit how their picture of reality is at least coherent (39-40). Wuketits writes that "From the point of view of survival, some of our conceptions of the outer world are simply better than others although they do not necessarily tell us something about reality as it actually is" (42). But what could he mean by better? Are some "conceptions of the outer world" thus more complete? The epistemology of Wuketits makes the notion of a world-in-itself obsolete (43). He recommends abandoning the notions of absolute knowledge and absolute truth (44). 